\title{
Microglial SMAD4 regulated by microRNA-146a promotes migration of microglia which support tumor progression in a glioma environment
}

\section{ABSTRACT}

Glioma tumors constitute a significant portion of microglial cells, which are known to support tumor progression. The present study demonstrates that transforming growth factor- $\beta$ (TGF $\beta$ ) signaling pathway in microglia in a glioma environment is involved in tumor progression and pathogenesis. It has been shown that the TGF $\beta$ level is elevated in higher grades of gliomas and its signaling pathway regulates tumor progression through phosphorylation of SMAD2 and SMAD3, which form a complex with SMAD4 to regulate target gene transcription. In an in vitro cell linebased model, increased protein levels of pSMAD2/3, total SMAD2/3 and SMAD4 were observed in murine BV2 microglia cultured in glioma conditioned medium (GCM), indicative of the activated TGF $\beta$ signaling pathway in microglia associated with glioma environment. Immunofluorescence labeling further revealed the expression of SMAD4 in microglial and non-microglial cells of human glioblastomas tissue in vivo. Functional analysis through shRNA-mediated stable knockdown of SMAD4 in microglia revealed the downregulation of the expression of matrix metalloproteinase 9 (MMP9), which has been shown to be involved in tumor progression and cell migration. Further, knockdown of SMAD4 in microglia decreased the migration of microglial cells towards GCM, indicating that SMAD4 promotes microglial migration in glioma environment. In addition, SMAD4 has been shown to be post-transcriptionally regulated by microRNA$146 a$, which was downregulated in microglia treated with GCM. Overexpression of miR-146a resulted in decreased expression of SMAD4 together with tumor supportive gene MMP9 in microglia, and subsequently suppressed microglial migration towards GCM, possibly through regulation of SMAD4. On the other hand, the cell viability assay revealed decreased viability of glioma cells when they were treated with conditioned 


\begin{abstract}
medium derived from SMAD4 knockdown microglia or miR-146a overexpressed microglia as compared to glioma cells treated with the medium from control microglial cells. Taken together, the present study suggests that microglial SMAD4 which is epigenetically regulated by miR-146a promotes microglial migration in gliomas and glioma cell viability.
\end{abstract}

\section{INTRODUCTION}

Gliomas are malignant brain tumors with a wide range of clinical features. Gliomas arise from the glial cells of the brain, progressing through the benign stage (WHO Grade I) to highly malignant (WHO Grades II to IV) stages. Higher grades of glioma are heterogeneous in nature, consisting of neoplastic cells, glioma-like stem cells, extensive vasculature and immune cells [13]. Microglia, the resident immune cells of the brain, form a significant portion of the infiltrating immune cell population in a tumor, making up to one-third of the tumor mass in some higher grade tumors $[4,5]$. As the first responders to any injury, insult or infection in the central nervous system (CNS), microglia become activated, secrete a variety of pro-inflammatory cytokines and exhibit phagocytic activity to clear tissue debris [6]. Subsequently, microglia facilitate repair and regeneration of the affected region in the CNS via release of growth factors and anti-inflammatory cytokines [7, 8]. Activated microglia exhibit neurotoxic and neuroprotective roles in neuropathology and based on their functions, microglia are categorized as the classical (pro-inflammatory) phenotype and the alternative (anti-inflammatory) phenotype $[9,10]$. Microglial function in glioma tumors is an alternative form of activation wherein microglia secrete cytokines and chemokines that are gliomagenic and support the growth of the tumor $[11,12]$. However, recent studies suggest that tumor-associated microglia express genes that are distinct from either activation state [13, 14], thus emphasizing the complex nature of tumor-associated microglia and its roles in a glioma microenvironment. This tumorigenic nature of microglia in glioma tumors may be attributed to molecular and epigenetic pathways that are altered by signaling molecules released from cancerous cells in the microenvironment.

Neoplastic cells within a tumor secrete a number of soluble cytokines, chemokines and growth factors that affect microglial motility, proliferation and phagocytosis $[15,16]$. A key signaling molecule that is highly enriched in the glioma microenvironment is the Transforming Growth Factor-beta (TGF $\beta$ ) which activates the TGF $\beta$ pathway that is mediated by SMAD2 and 3, substrates for the TGF $\beta$ family of receptors. Upon binding of the TGF $\beta$ ligand to its receptor, the SMAD2/3 complex is phosphorylated and coupled with the common mediator SMAD4, translocated to the nucleus where the complex regulates the transcription of TGF $\beta$ responsive genes [17]. TGF $\beta$ is a known inhibitor of cell cycle progression [18] and thus, functions as a tumor suppressor in the early stages of certain cancers. On the contrary, TGF $\beta$ signaling can be pro-tumorigenic by inducing genes that promote tumorigenic aspects of glioma progression such as angiogenesis [19], metastasis [20,21] and epithelialmesenchymal transition [22]. Hyperactive TGF $\beta$ signaling is associated with certain subtypes of glioblastoma tumors, such as the mesenchymal subset and contributes to aggressiveness of the tumor and poor prognosis in patients [23-25]. In tumors with activated TGF $\beta$ signaling such as hepatocellular cancer, elevated SMAD4 has been shown to mediate tumor promoting signaling [26], while in other cancers such as pancreatic cancer, deletion of SMAD4 is associated with tumor progression and metastasis [27, 28]. Therapeutic approaches using TGF $\beta$ antagonists and oligonucleotides coding anti-sense TGF $\beta 2$ have proven successful in reversal of TGF $\beta$-aided immunosuppression in glioma $[29,30]$. However, systemic inhibition of TGF $\beta$ pathway can lead to unfavorable effects as TGF $\beta$ is involved in several cellular signaling pathways. This led us to investigate alternate specific mechanisms by which the TGF $\beta$ signaling pathways can be disrupted to attenuate the tumor supportive phenotype of microglia. Moreover, the role of SMAD4 in microglial functions in gliomas has been poorly understood and hence, this study is aimed to understand the role of SMAD4 in tumor-associated microglia in mediating tumor progression.

In addition to altered signaling pathways, activated microglia in different neuropathologies exhibit dysregulated epigenetic mechanisms such as chromatin modifications, changes in gene-specific histone acetylation and methylation and differential microRNA (miRNA) expression [31, 32]. In particular, miRNAs have emerged as a central class of epigenetic mediators that post-transcriptionally regulate gene expression [33]. Dysregulation of miRNAs in activated microglia has been shown to contribute to development and progression of neurodegenerative diseases and brain injuries [33]. A global miRNA microarray analysis of activated primary microglial cells identified several miRNAs that were differentially expressed in activated microglia. The micro RNA 146a (miR-146a) was found to be upregulated in activated microglia as compared to control microglia (unpublished data). MiR-146a, which is enriched in activated macrophages and microglia [34], has been shown to target and suppress mediators of the nuclear factor kappa-light-chain-enhancer of activated B cells (NFKB) signaling pathway in activated microglia and astrocytes, thereby functioning as a negative feedback regulator of microglial activation $[35,36]$. In addition, miR-146a was reported to target Notch1 in glioma cells 
and further inhibit the process of gliomagenesis by suppressing migration and proliferation of cancer cells [37]. Further, our bioinformatics analysis predicted miR-146a to target SMAD4. Given the important role of miR-146a in microglia activation and gliomagenesis and its putative effect on SMAD4, this study attempted to understand the role of miR-146a and its putative target SMAD4 in microglia functions in tumor progression in glioma environment.

It was hypothesized that altered molecular and epigenetic mechanisms regulate the tumor supportive behavior of glioma-associated microglia. In this study, SMAD4, a mediator of the TGF $\beta$ signaling pathway was upregulated in microglia exposed to glioma conditioned medium and was found to be robustly expressed in microglia associated with human glioblastoma tissues. Stable loss of SMAD4 in microglia decreased expression level of a tumor promoter, MMP9, which resulted in decreased migratory potential of microglia in a transwell migration assay. In addition, miR-146a which was predicted to target SMAD4, was downregulated in microglia exposed to glioma conditioned medium treatment and regulated the expression levels of tumor supportive gene MMP9 in microglia. Overall, the present study implicates the role of miR-146a-SMAD4 in regulating microglial functions in glioma tumors.

\section{RESULTS}

\section{Glioma conditioned medium induced phosphorylation of SMAD2 and SMAD3 in microglia}

To understand the effect of glioma microenvironment on microglia, BV2 microglial cells were cultured in glioma conditioned medium (GCM) derived from $\mathrm{C} 6$ glioma cells. The concentration of TGF $\beta$ in the GCM was assessed to be $\sim 5 \mathrm{ng} / \mathrm{ml}$ as compared to undetectable levels of TGF $\beta$ in serum containing medium (Figure 1A). First, the expression of total and phosphorylated SMAD2/3, which mediates the TGF $\beta$ signaling, was determined in GCM-treated microglia. Western blot analysis showed an increase in the phosphorylated levels of SMAD2 and SMAD3 in GCM treated microglia as compared to control microglia (Figure 1B, 1C). Upon phosphorylation of SMAD2 and SMAD3, the complex has been shown to bind to SMAD4 and translocate to the nucleus [38]. Confocal imaging revealed a co-localization of the pSMAD2/3 with SMAD4 in nuclei of microglial cells treated with GCM (Figure 1D). Further, immunocytochemistry revealed increased co-localization of the SMAD4 and total SMAD2/3 in microglia treated with GCM as compared to control cells (Figure 1E), suggesting that the TGF $\beta$ pathway is activated in GCMtreated microglia.

\section{Microglia treated with GCM show increased expression of SMAD4 and tumor supportive genes}

As SMAD2/3 forms a complex with SMAD4 to regulate TGF $\beta$ responsive genes, the effect of glioma microenvironment on SMAD4 expression in microglia was determined by western blot and immunocytochemistry. Upregulation of SMAD4 protein expression was clearly evident in microglia treated with GCM as compared to that of control (Figure 2A, 2B). Concomitantly, GCM treated microglial cells showed an upregulation in proteins involved in TGF $\beta$ signaling pathway such as matrix metalloproteinase 9 (MMP9) and vascular endothelial growth factor (VEGFa) (Figure 2A, 2B), suggesting that glioma-associated microglia exhibit upregulated expression of tumor supportive factors.

\section{SMAD4 is expressed in microglia associated with human glioblastoma samples}

In light of the above results, we sought to validate the expression of SMAD4 in human glioblastoma tissue to better understand its role in glioma pathogenesis. An analysis of the expression profiling data of glioblastoma samples in The Cancer Genome Atlas database using Oncomine software showed a significant increase (3.271 fold) in the expression of SMAD4 (Reporter ID: 202527_s_at) mRNA in glioblastoma tissues $(\mathrm{n}=542)$ when compared with non-malignant brain tissue samples available in the database (Figure 3A) [39].

In the present study, double immunofluorescence analysis was performed to determine SMAD4 protein expression in glioblastoma tissues (Figure 3B). Confocal imaging showed expression of SMAD4 in Iba1-positive microglia, as well as non-microglial cells in different tissue samples (Figure 3B). The Iba1-immunoreactive cells appeared to be an amoeboid or rounded phenotype, indicative of activated state of the cell type. High magnification images show evident nuclear expression of SMAD4 in Iba1 positive microglia (Figure 3B). Quantitative analysis of Iba1-positive cell bodies revealed a high percentage of microglia in the tumor samples (Figure 3C).

\section{SMAD4 regulates the expression of tumor supportive factor MMP9}

In order to ascertain the role of SMAD4 in microglia, stable knockdown of SMAD4 in microglia was carried out by transduction of small-hairpin RNA (shRNA) against the Smad4 gene. ShRNA-mediated silencing of the Smad4 gene resulted in $90 \%$ decrease in mRNA levels of Smad4 (Figure 4A) and 80\% decrease in the protein level of SMAD4 (Figure 4A, 4C). A downregulation of MMP9 at mRNA and protein level was observed in microglia 
A

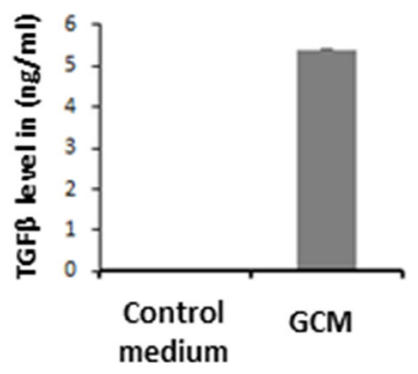

D
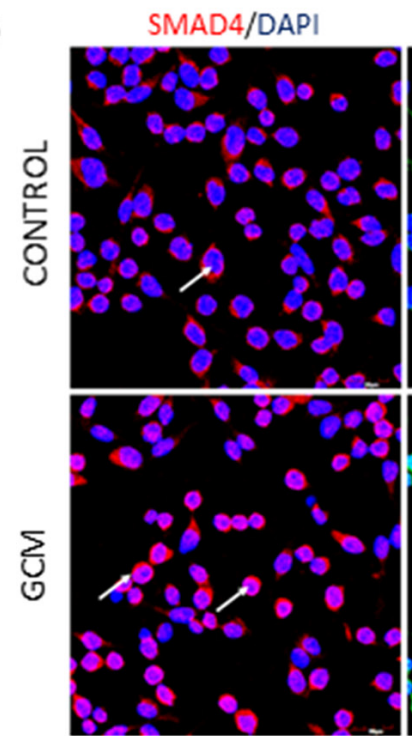

E
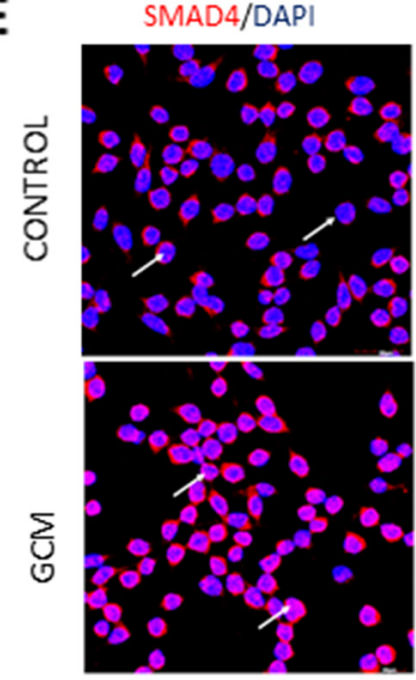

B

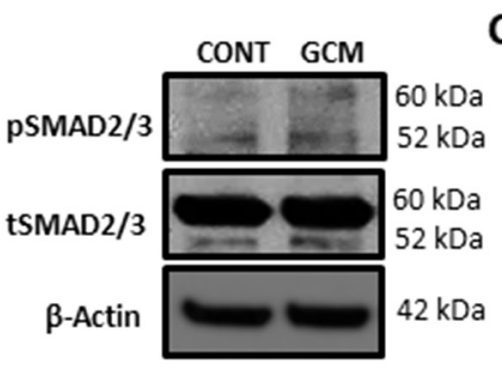

C

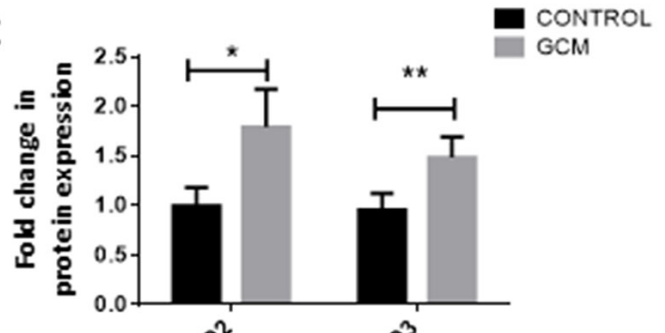

pSMAD2/3/DAPI

pSMAD2/3/SMAD4/DAPI

PSMAD2/3/SMAD4
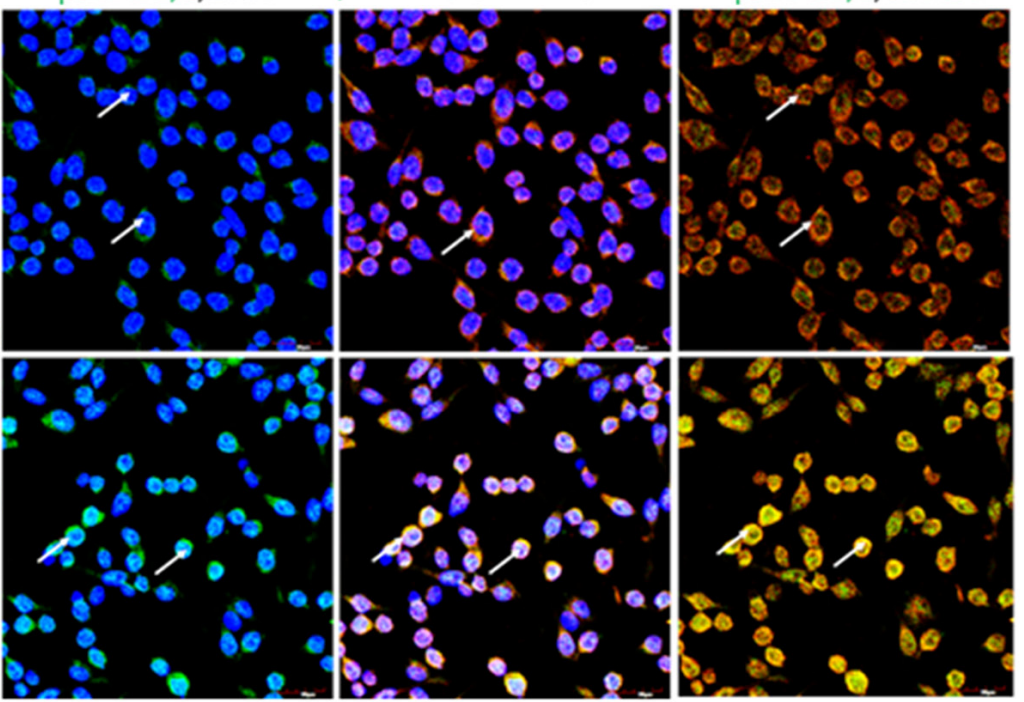

tSMAD2/3/DAP|

tSMAD2/3/SMAD4/DAPI

tSMAD2/3/SMAD4
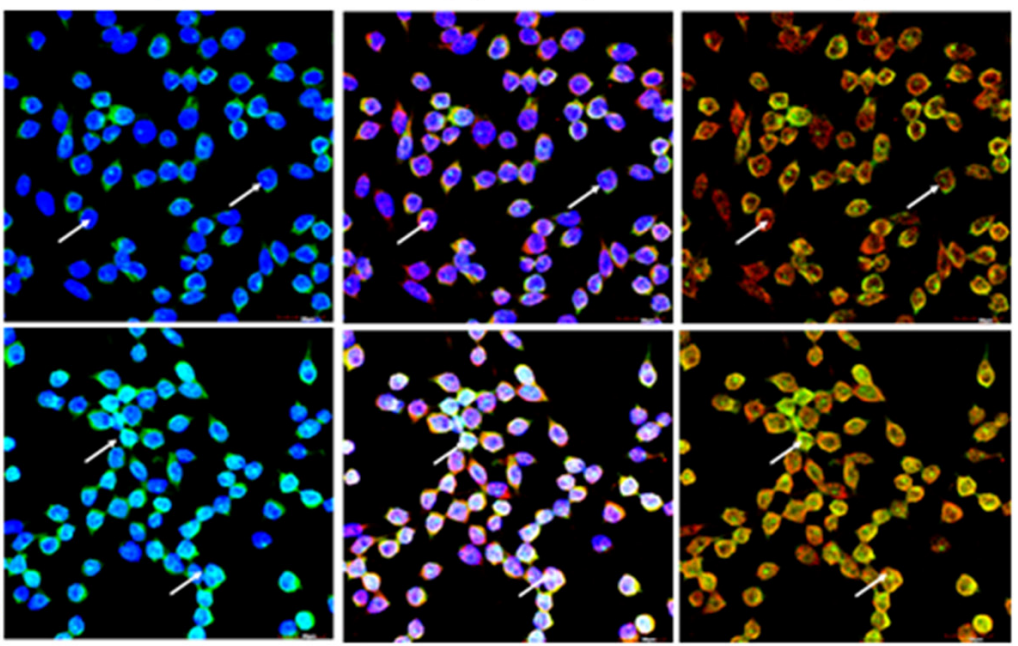

Figure 1: GCM induces TGF $\beta$ signaling pathway in microglia. ELISA assay quantification revealed that GCM contains $\sim 5 \mathrm{ng} / \mathrm{ml}$ of TGF $\beta$ (A). Western Blot (B) shows an increase in phosphorylated form of pSMAD2/3 in microglia treated with GCM when compared with control. Histogram depicts densitometric quantification of pSMAD2/3 normalized against total SMAD2/3 expression (C) Data represent mean $\pm \mathrm{SD},(\mathrm{n}=4)$, Students $t$-test, ${ }^{*} p<0.05,{ }^{*} p<0.01$. Confocal images show pSMAD2/3 (green, D), total SMAD2/3 expression (green, E) and SMAD4 expression (red, D, E) in BV2 microglia (indicated by arrows). Cell nuclei are labelled with DAPI (blue). GCM increases immunofluorescence intensity of $\mathrm{pSMAD} 2 / 3$ as compared to control cells (D). Immunocolocalization of pSMAD2/3, total SMAD2/3 and SMAD4 reveals that $\mathrm{pSMAD2/3}$ and total SMAD2/3 colocalize with SMAD4 in microglia treated with $\operatorname{GCM}(\mathrm{D}, \mathrm{E})$. Scale bar= $30 \mu \mathrm{m}$. 


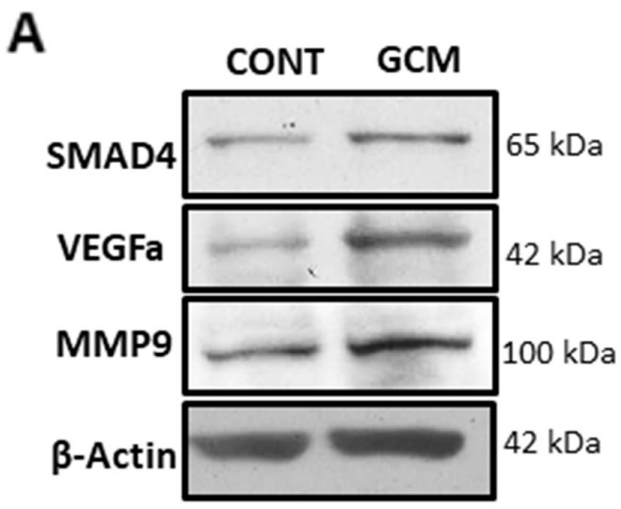

B

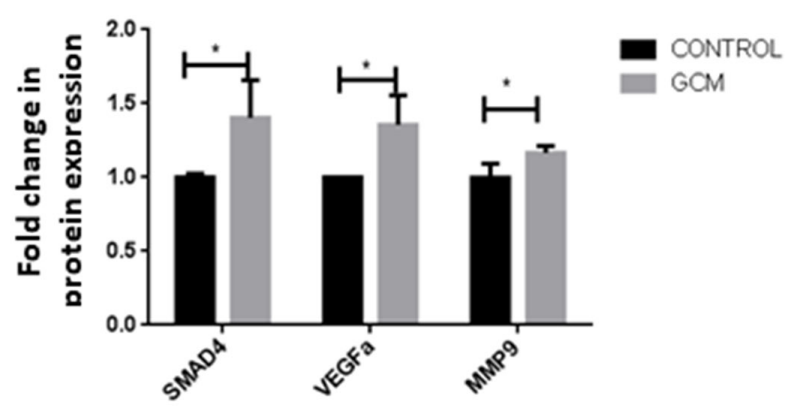

Figure 2: SMAD4 and tumor supportive genes MMP9 and VEGFa are upregulated in glioma associated microglia. Western blot analysis shows an increase in SMAD4 protein levels and tumor supportive genes, VEGFa and MMP9 in BV2 microglia upon GCM treatment (A). Histogram depicts densitometric quantification of protein levels of SMAD4, VEGFa and MMP9 in microglia exposed to GCM (B). Data represent Mean $\pm \mathrm{SD},(\mathrm{n}=3-5)$, Students $t$-test, ${ }^{*} p<0.05$.

A

mRNA levels of SMAD4 expression between non-malignant brain tissue and brain glioblastoma

\begin{tabular}{lll}
\hline & $\begin{array}{l}\text { Fold } \\
\text { Change }\end{array}$ & P-Value \\
\hline SMAD4 & 3.271 & $8.40^{-11}$ \\
\hline
\end{tabular}

B

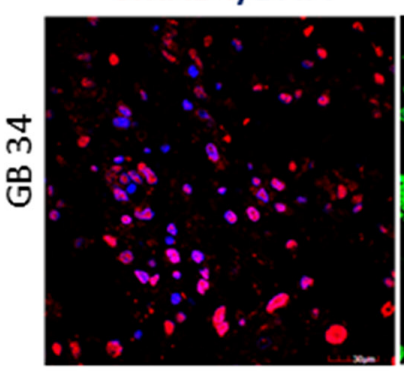

Iba1/DAPI

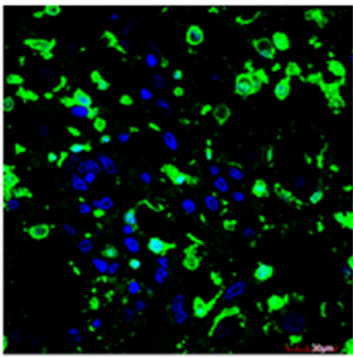

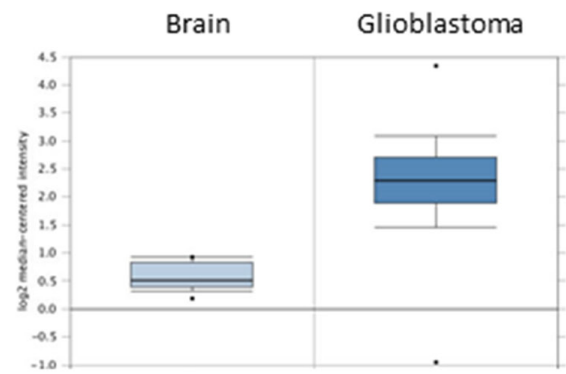

SMAD4/Iba1/DAPI SMAD4/Iba1/DAPI

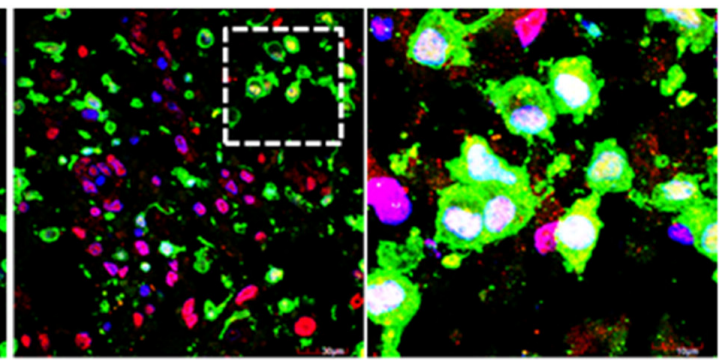

C

\begin{tabular}{|cc|} 
Tumor Sample & $\begin{array}{c}\text { \% microglial } \\
\text { population }\end{array}$ \\
\hline GB 25 & 9.60 \\
\hline GBO 24 & 11.44 \\
\hline GB 28 & 14.90 \\
\hline GBO 26 & 18.04 \\
\hline GB 21 & 24.36 \\
\hline GB 22 & 35.58 \\
\hline GB 34 & 50.10 \\
\hline
\end{tabular}

Figure 3: SMAD4 is expressed in microglia associated with human glioblastoma samples. An analysis of the TCGA profiling data reveals a significant increase in SMAD4 mRNA levels in brain glioblastoma tissue as compared to normal non-malignant tissue (A). Panel shows expression of SMAD4 in human glioblastoma tumor tissue (GB 34) (B). Note that there is evident expression of SMAD4 (red) expression in Ibal positive microglial cells (green). Cell nuclei are labelled with DAPI (blue). Scale $=30 \mu \mathrm{m}$ (low magnification), Scale $=10 \mu \mathrm{m}$ (high magnification). Table depicts the percentage of Ibal positive microglial cells per tumor (C). 
after knockdown of SMAD4 compared to cells transduced with the empty vector, which served as a negative control (Figure 4B, 4C). This suggests that SMAD4 regulates the expression of tumor supportive factor, MMP9 in microglia.

\section{ShRNA-mediated silencing of SMAD4 suppresses the migration of microglia towards glioma conditioned medium}

The transwell migration assay was performed, wherein microglial cells were seeded in serum-free medium in the upper chamber of a transwell insert and allowed to migrate towards the lower chamber containing GCM or chemoattractants such as TGF $\beta$ and EGF, to assess the migratory potential of microglia towards GCM (Figure 5A-5D). There is a significant increase in the number of microglial cells migrating towards GCM (Figure 5B, 5E) in the lower chamber as compared to the number of microglial cells migrating to serum containing medium which served as a control (Figure 5A). In addition, microglial cells showed increased migration towards chambers containing soluble TGF $\beta$ and EGF (Figure 5C, 5D, 5E) as compared to control.

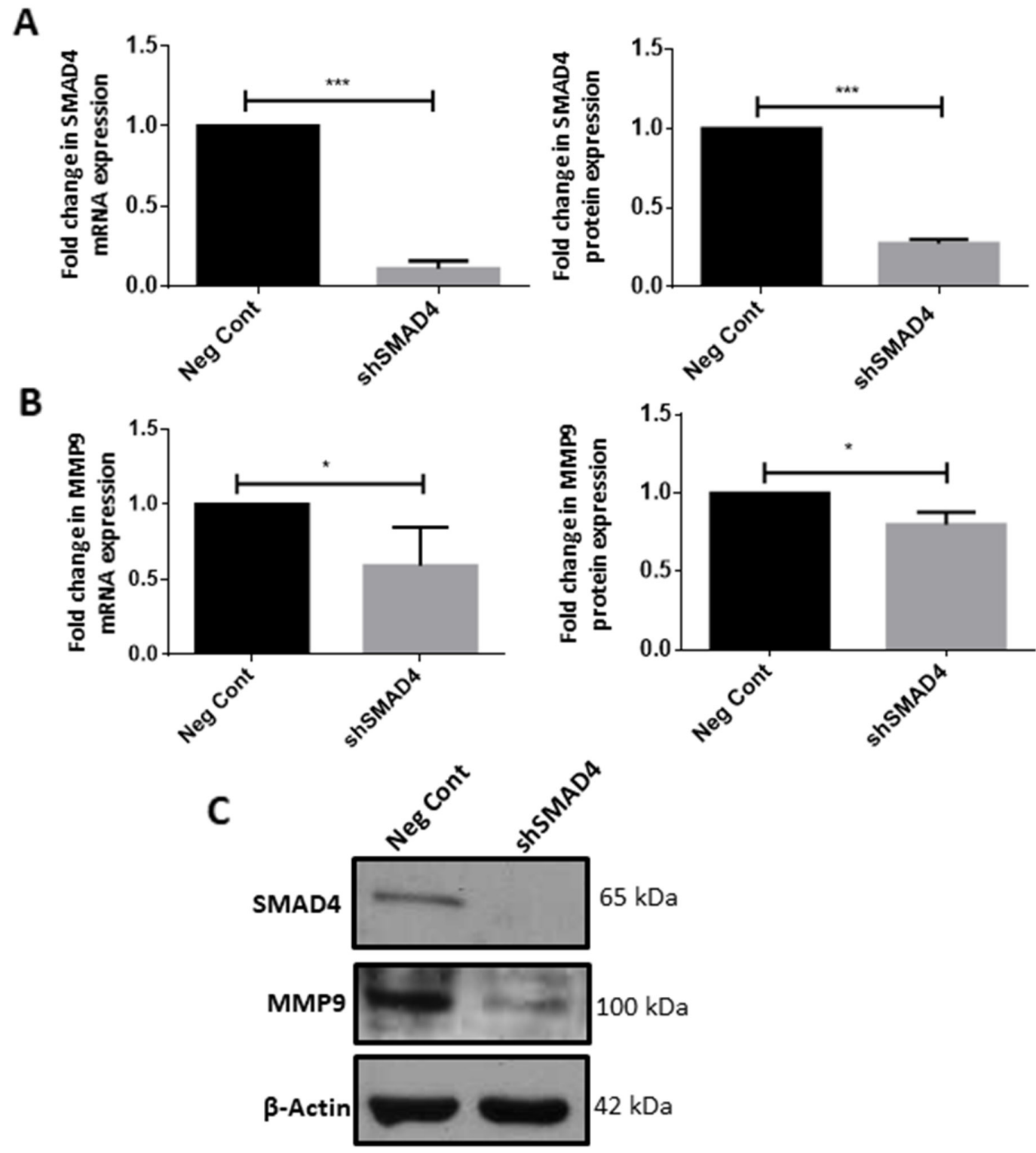

Figure 4: SMAD4 regulates expression of tumor supportive factor MMP9 in microglia. Quantitative RT-PCR and western blot analyses shows a decrease in mRNA and protein expression of SMAD4 in shSMAD4 BV2 cells as compared to negative control (A, C). Data represent Mean $\pm \mathrm{SD},(\mathrm{n}=3)$, Students $t$-test, ${ }^{* * *} p<0.001$. Quantitative RT-PCR and western blot analyses show that shRNAmediated knockdown of SMAD4 resulted in a decrease in the mRNA and protein expression of MMP9 (B, C). Mean $\pm \mathrm{SD},(\mathrm{n}=4)$, Students $t$-test, ${ }^{*} p<0.05$. 
Further, the role of SMAD4 in the migration of microglia towards GCM was studied. A significant decrease in the number of shSMAD4 cells migrating towards the serum containing medium in the lower chamber, was observed as compared to control cells which were transfected with empty vector (Figure 5F, $5 \mathrm{G}, 5 \mathrm{~J})$. This indicates that SMAD4 plays a significant role in the migratory potential of microglia. On the other hand, upon exposure to GCM, there was an increase in the number of migrating control and shSMAD4 microglial cells compared to that of control and shSMAD4 microglial cells, respectively. However, the increase in migration of shSMAD4 microglial cells exposed to GCM was significantly less than that of control microglial cells

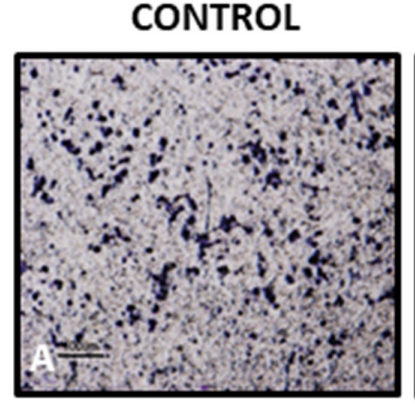

TGF $\beta$

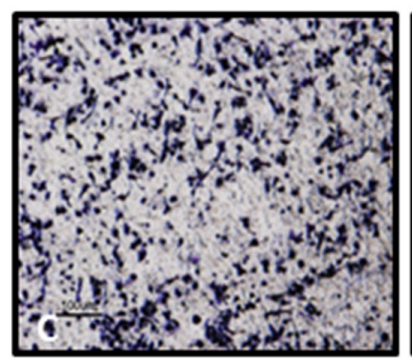

GCM

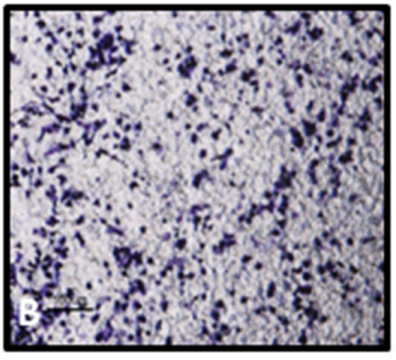

EGF

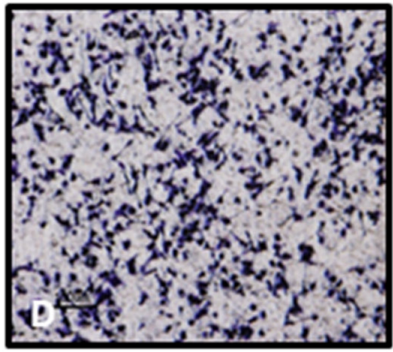

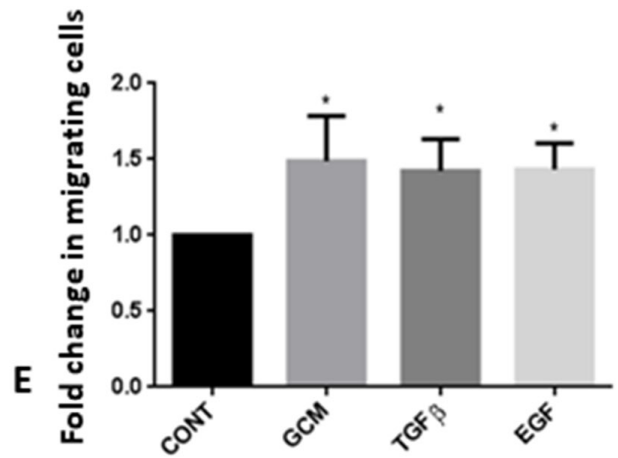
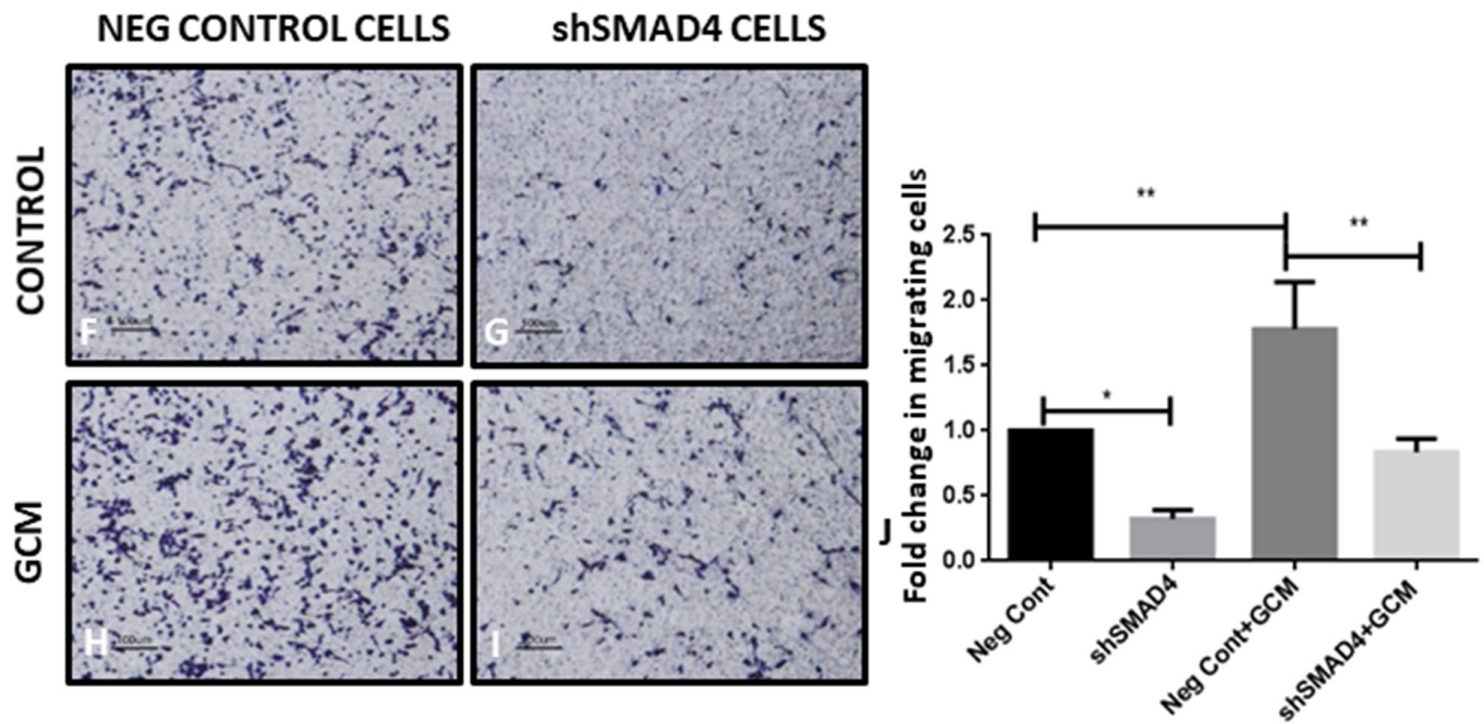

Figure 5: shRNA-mediated knockdown of SMAD4 suppresses microglial migration. Trans-well membrane image panels show an increase in the number of migrated microglial cells (purple) after exposure to GCM (B), TGF $\beta$ (C) and EGF (D) as compared to cells exposed to serum containing medium (A). Histogram depicts fold change in migrating cells exposed to GCM, TGF $\beta$ and EGF as compared with control group (E). Data represent mean $\pm \mathrm{SD},{ }^{*} p<0.05,{ }^{* *} p<0.01,(\mathrm{n}=3)$. There was a decrease in the number of migrated shSMAD4 microglial cells (purple) in response to GCM and serum containing medium (I, G) as compared to negative control (Neg Cont) microglial cells exposed to GCM and serum containing medium $(\mathbf{H}, \mathbf{F})$. Histogram depicts fold change in migrating cells $(\mathbf{J})$. Data represent mean $\pm \mathrm{SD},(\mathrm{n}=3),{ }^{*} p<0.05,{ }^{* *} p<0.01$. 
exposed to GCM (Figure 5H, 5I, 5J). In addition, GCMinduced migration index of both control and shSMAD4 microglial cells appear to be comparable (Figure 5J), suggesting that factors involving TGF $\beta$ pathway present in GCM could play a role in migration of microglia.

\section{Microglial conditioned medium from shSMAD4 cells inhibits glioma viability}

Microglial cells have been shown to promote glioma progression through secretion of factors that aid in tumor growth. In the present study, the viability of glioma cells in response to conditioned medium from microglia was evaluated using an MTS assay and alamar blue assay. The results indicate that there is a significant increase in cell viability (Figure 6A, 6B) of glioma cells after 24,48 and $72 \mathrm{~h}$ of treatment with medium derived from control microglial cells, confirming that microglial cells secrete factors that promote glioma cell growth. In order to determine the effect of knockdown of SMAD4 in microglia on glioma cell viability, glioma cells were treated with conditioned medium derived from shSMAD4 microglial cells. The results indicate that there is a decrease in viability of glioma cells when treated with medium from SMAD4 knockdown microglial cells (Figure $6 C)$, suggesting that suppression of SMAD4 in microglia decreases the viability of glioma cells. This was further confirmed with an alamar blue assay wherein a significant decrease in reduction of alamar blue was observed in vitro after treatment of glioma cells with medium derived from shSMAD4 microglial cells as compared to the corresponding control (Figure 6D).

\section{MiR-146a regulates SMAD4 expression in GCM treated microglia}

In order to delineate the epigenetic mechanisms that regulate SMAD4 expression in glioma-associated microglia, we examined the 3'UTR of the Smad4 mRNA sequence to identify miRNA binding sites. TargetScan algorithms software (http://www.targetscan.org/mmu_71/) revealed putative complimentary binding site for miR146a in the 3'UTR of Smad4 (Figure 7A). Given the role of miR-146a in activation of microglia [36, 40, 41], its role in the tumor supportive phenotype of microglia was determined. The quantitative RT-PCR analysis showed that the expression level of miR-146a-5p was significantly decreased in glioma-associated microglia as compared to control cells (Figure 7B). This is concurrent with an increase in mRNA and protein levels of SMAD4 (Figure 7B, 2A), demonstrating an inverse relationship between miR-146a and SMAD4 in microglia.

Further, 3'UTR luciferase assay was performed to confirm that SMAD4 is a target of miR-146a. BV2 microglial cells were transfected with a luciferase vector containing the 3'UTR of the mouse Smad4 gene together with miR-146a overexpression (mimics) or scrambled probes. A significant decrease in the luciferase activity in BV2 microglia was observed upon co-transfection of the mimics and the luciferase vector, indicating that the miR-146a binds to the 3'UTR of Smad4 in luciferase vector (Figure 7C). Transfection efficiency of the miRNA overexpression and inhibition was determined by examining the levels of the miR-146a in microglial cells after transfection of mimics and inhibitors. Overexpression of miR-146a mimics was observed to increase miR-146a levels in microglia by nearly 400 -fold while inhibition of the miR-146a resulted in a $\sim 50 \%$ decrease in miR-146a levels (Figure 7D). The mRNA expression of SMAD4 after overexpression and inhibition of the miR-146a was analyzed. MiR-146a mimic transfection resulted in decrease in mRNA and protein expression levels of SMAD4 and conversely, inhibition of miRNA function resulted in an increase in the mRNA and protein levels of SMAD4 (Figure 7E, 7F, 7G) in microglia, suggesting that miR-146a directly targets SMAD4 in microglia.

In order to understand the functional relationship between miR-146a and SMAD4 in GCM-induced microglia, loss-of and gain-of function experiments were carried out. MiR-146a overexpression was found to significantly decrease SMAD4 expression at protein levels in microglia treated with GCM, as determined by western blot (Figure 8A, 8C). In contrast, inhibition of the miR-146a resulted in a marginal increase in the protein levels of SMAD4 in microglia treated with GCM as revealed by western blot analyses (Figure 8B, $8 \mathrm{D})$. Immunocytochemistry analysis also revealed that miR-146a overexpression with mimics decreased the expression of SMAD4 in microglia treated with or without GCM as compared to that transfected with scrambled probes (Figure 8E). This suggests that miR-146a regulates SMAD4 expression in glioma-associated microglia.

\section{MiR-146a regulates the expression of MMP9 in microglia and suppresses migration of microglia towards GCM}

Microglia treated with GCM showed an induction of tumor promoter gene MMP9, concomitant with an increase in SMAD4 level. In order to determine if miR146a regulates tumor supportive gene expression in microglia, expression of MMP9 upon overexpression and knockdown of miR-146a was analyzed. Overexpression of the miR-146a in microglia resulted in a significant suppression of MMP9 protein expression while inhibition of miR-146a was found to increase MMP9 expression (Figure 9A, 9B). In addition, overexpression of miR-146a in microglia resulted in a significant decrease in migration of microglia towards GCM in a transwell migration assay (Figure 9C-9G), indicating that miR-146a suppresses microglial migration through regulation of SMAD4 and its downstream gene MMP9. 
A
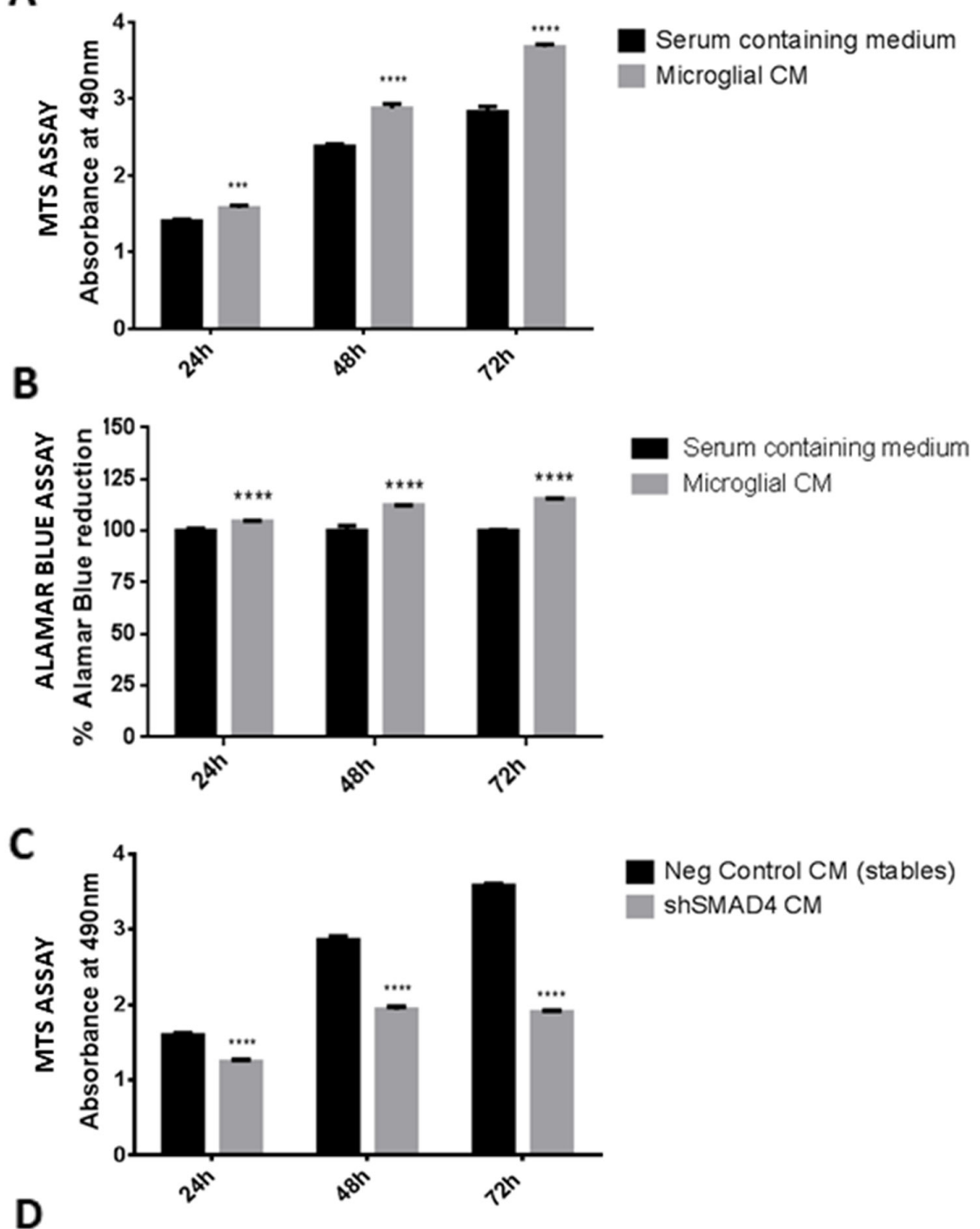

Neg Control CM (stables)

ShSMAD4 CM

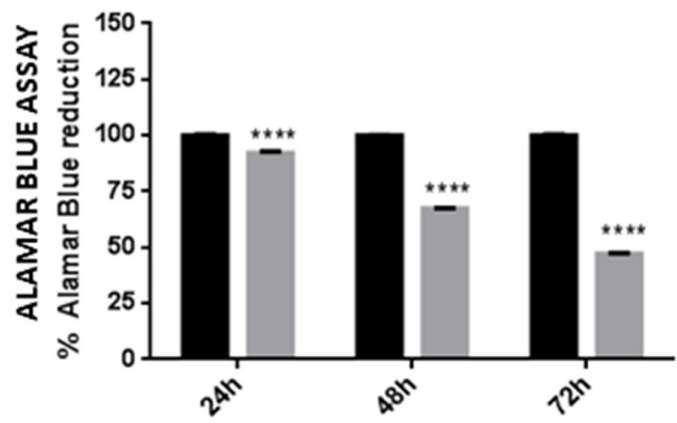

Figure 6: Effect of conditioned medium derived from shSMAD4 knockdown microglial cells on glioma cell viability. Histogram depicts MTS assay absorbance values at 24,48 and $72 \mathrm{~h}$ after treatment of glioma cells with conditioned medium derived from microglia. A significant increase in glioma viability was observed after treatment with microglia conditioned medium at all time points (A). This was further confirmed using alamar blue viability assay wherein an increase in $\%$ of reduction of alamar blue was observed in glioma cells treated with microglia conditioned medium at all time points (B). Histogram further shows the MTS assay absorbance values at 24, 48 and $72 \mathrm{~h}$ treatment of glioma cells with conditioned medium derived from shSMAD4 microglial cells (C). A decrease in absorbance values indicates a decrease in viability of glioma cells after treatment with conditioned medium from shSMAD4 cells as compared to glioma cells treated with negative control medium (C). In addition, alamar blue assay results (D) show a decrease in percentage of alamar blue reduction in glioma cells treated with medium from shSMAD4 microglia as compared to glioma cells treated with negative control medium. Data represent Mean $\pm \mathrm{SD},(\mathrm{n}=4),{ }^{* * *} p<0.001,{ }^{* * * *} p<0.0001$. 


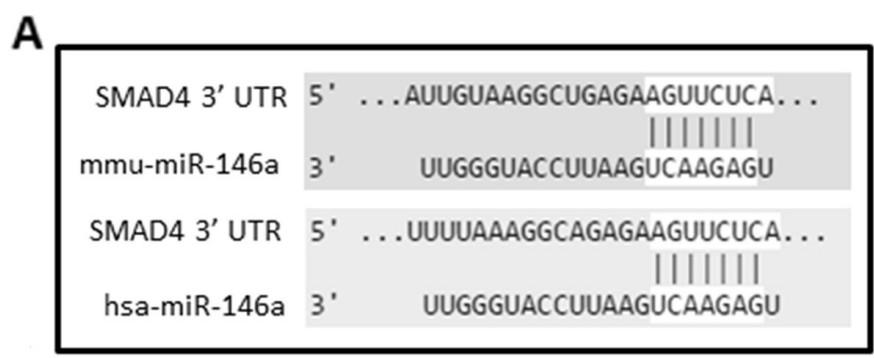

B

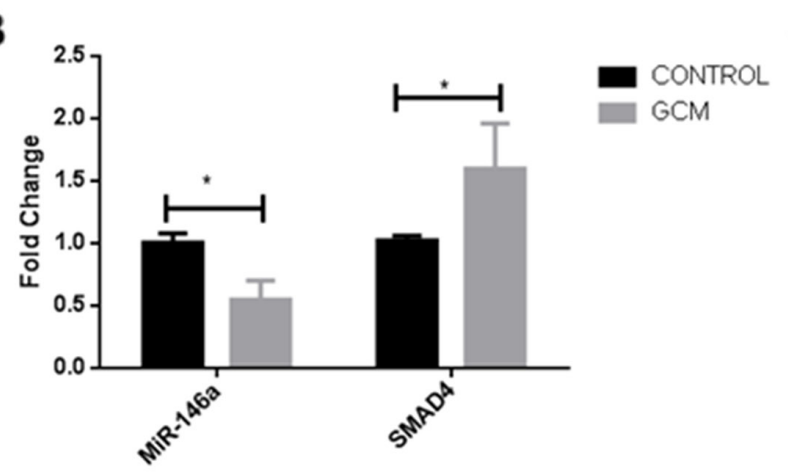

C

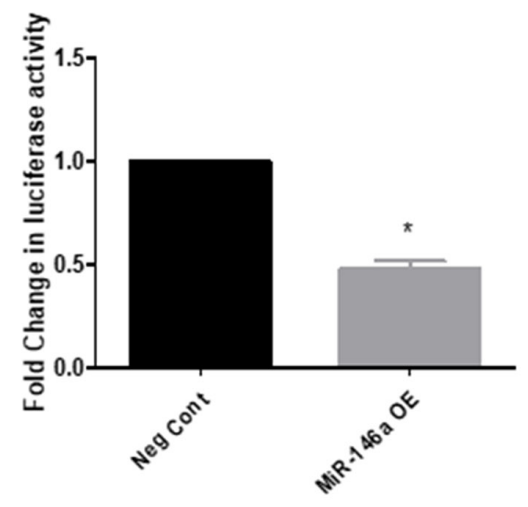

$\mathbf{E}$

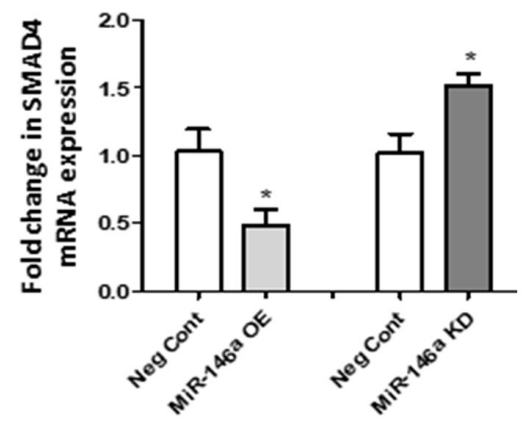

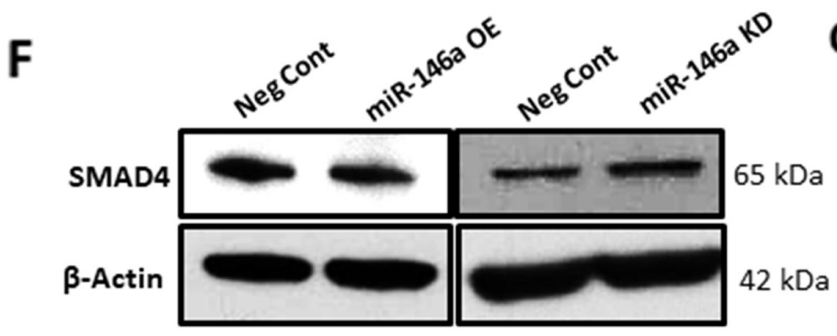

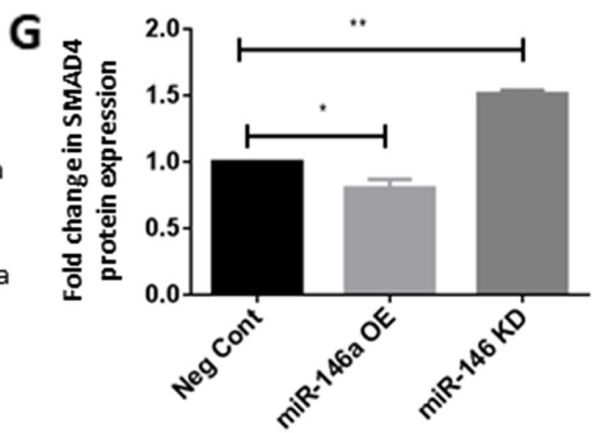

Figure 7: MiR-146a is downregulated in GCM treated microglia and targets SMAD4. TargetScan software predicted that miR-146a putatively binds to 3'UTR of SMAD4 mRNA (A). Histogram depicts a significant decrease in the levels of miR-146a and a significant increase in mRNA levels of SMAD4, indicating an inverse relationship between SMAD4 and miR-146a in microglia treated with GCM (B). Histogram shows a significant decrease in the luciferase activity in cells co-transfected with miR-146a mimic and luciferase vector as compared to cells co-transfected with scrambled control miRNA and luciferase vector, indicating that miR-146a targets SMAD4 (C). Data represent mean $\pm \mathrm{SD},(\mathrm{n}=3)$, Students $t$-test, ${ }^{*} p<0.05$. MiRNA mimics and inhibitor transfection efficiency was verified using qRTPCR. Histogram shows an about 400-fold increase in miR-146a levels in microglia after mimic transfection and about $50 \%$ decrease in miR-146a levels after inhibitor transfection (D). Data represent mean $\pm \mathrm{SD},(\mathrm{n}=3)$, Students $t$-test, ${ }^{*} p<0.05$. Histogram shows a decrease in the mRNA levels of SMAD4 upon overexpression of miR-146a and conversely an increase in SMAD4 mRNA upon inhibition of miR-146a (E). Data represent mean $\pm \mathrm{SD},(\mathrm{n}=3)$, Students $t$-test, ${ }^{*} p<0.05$. Western blot $(\mathbf{F})$ and densitometry analysis $(\mathbf{G})$ confirm that overexpression of miR-146a suppresses SMAD4 protein levels and inhibition of miR-146a increases SMAD4 protein level as compared to scrambled probe transfected cells. Data represent mean $\pm \mathrm{SD},(\mathrm{n}=3)$, Students $t$-test, ${ }^{*} p<0.05,{ }^{* *} p<0.01$. MiR-146a OE- MiR-146a overexpression; MiR-146a KD-MiR-146a knockdown. 


\section{miR-146a overexpression in microglia suppresses glioma viability and growth}

To determine the effect of miR-146a overexpression in microglia on glioma cell viability, glioma cells were treated with conditioned medium derived from miR146a overexpressed microglial cells. The MTS results indicate that there is a decreased viability of glioma cells across different time points after treatment with miR-146a overexpressed microglia-derived medium as compared with that of scrambled control transfected cells (Figure 10A). This was further confirmed with an alamar blue assay wherein a significant decrease in alamar blue reduction was observed in vitro after treatment of glioma cells with medium from miR-146a overexpressed microglial cells (Figure 10B), indicating that overexpression of miR-146a in microglia decreased the viability of glioma cells.
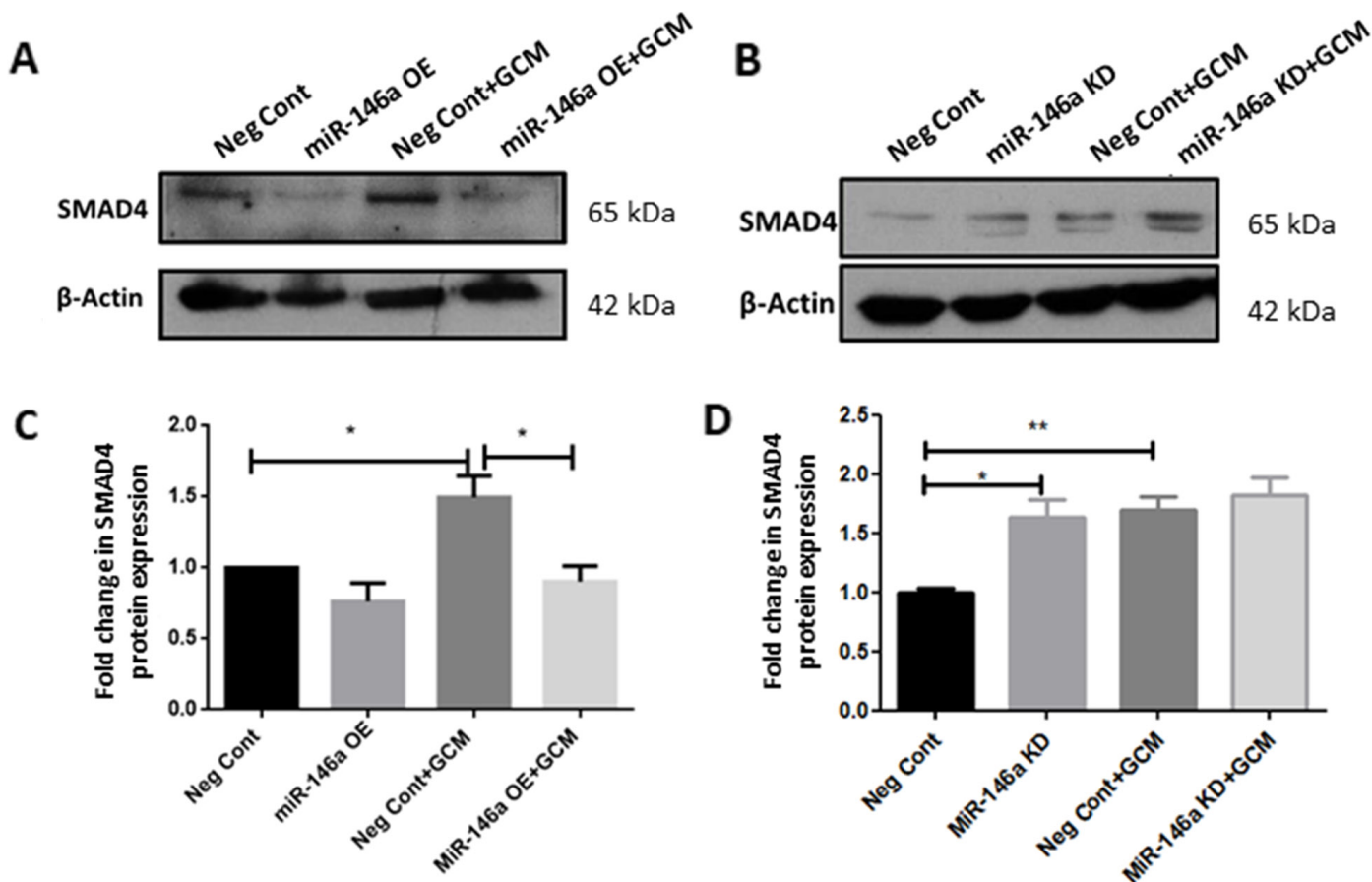

E
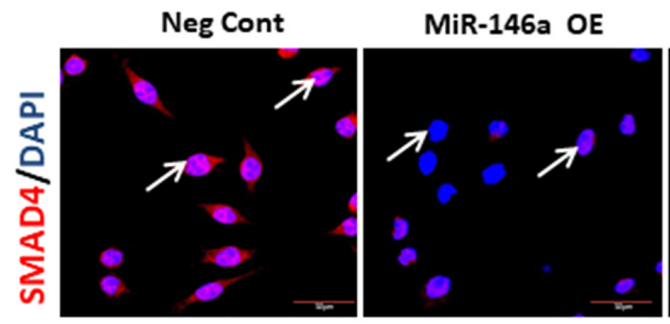

\section{D}
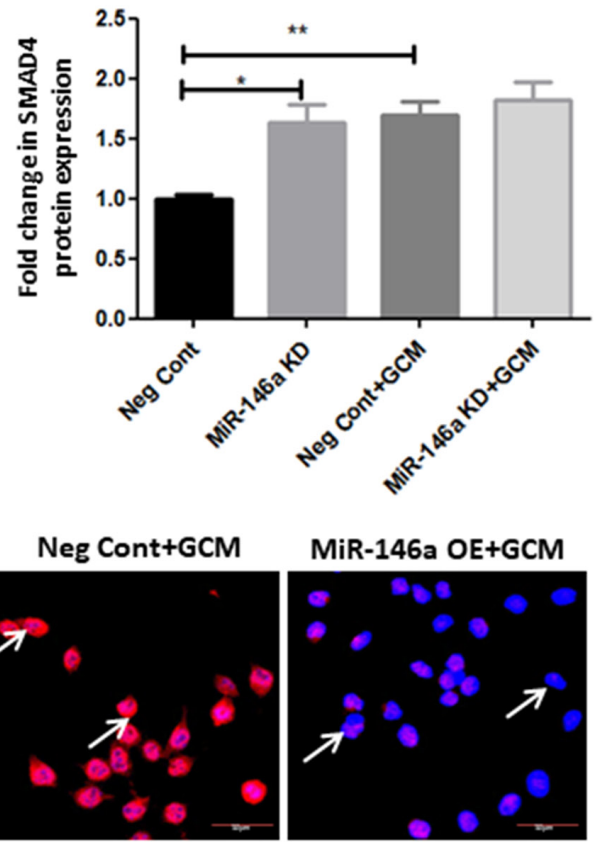

\section{DISCUSSION}

It is well documented that microglia play diverse roles, either detrimental or beneficial, during CNS pathology [6]. In the normal healthy brain, microglia monitor the brain microenvironment for pathogens and injury and are involved in functions such as neuronal synapse formation, maintenance and pruning [42-44]. Upon activation, the microglia with processes rapidly transform into amoeboid phenotype and are involved in phagocytosis of debris in brain parenchyma [45]. In the present study, microglia within gliomas exhibit primarily amoeboid phenotype, suggesting that they are activated, probably in response to the glioma secretome which consists of signaling molecules released by neoplastic and non-neoplastic cells such as vascular endothelial cells, astrocytes and cancer stem cells of the tumor that lie in

Figure 8: MiR-146a regulates SMAD4 in GCM-treated microglia. Western blot analyses show that transfection of microglial cells with miR-146a mimics suppressed the GCM induced induction of SMAD4 protein (A, C) Data represent mean $\pm \mathrm{SD},(\mathrm{n}=3),{ }^{*} p<0.05$. MiR-146a inhibition increases the protein levels of SMAD4 upon GCM treatment of microglia as seen by western blot analyses and densitometry quantification (B, D). Data represent mean $\pm \mathrm{SD},(\mathrm{n}=5),{ }^{*} p<0.05$. Immunofluorescence labelling shows that miR-146a overexpression attenuated SMAD4 expression (red) in BV2 microglia nuclei with or without GCM treatment as compared to cells transfected with scrambled miRNA (Neg Cont) probes (E). DAPI-nuclei staining, blue. Scale bar=30 $\mu \mathrm{m}$. MiR-146a OE- MiR-146a overexpression; MiR-146a KD-MiR-146a knockdown. 
spatial proximity to microglial cells. This is supported by recent experimental evidence, which showed that microglia exposed to glioma conditioned medium in vitro and microglia associated with glioma tumors in mice models in vivo exhibit an amoeboid phenotype that is characteristic of a state of activation [46-48]. Further, the glioma tumors analyzed in the present study showed a high percentage of Iba1-positive microglial cells, with certain glioblastoma tumors hosting nearly $25 \%-50 \%$ of microglial cells in the tumor mass. A higher frequency of microglial cells in the tumor may be attributed to migration of microglia in the brain parenchyma in response to factors released by the glioma cells as can be seen in the in vitro migration assay. Several studies have shown that soluble factors such as EGF [49, 50] and TGF $\beta$ [51] serve as potent chemotactic factors in tumors and may promote migration of microglia towards the tumor as observed in the present study.
In addition to its role as a chemoattractant, the TGF $\beta$ ligand activates an anti-inflammatory signaling pathway in microglia, exerting an opposing effect on pro-inflammatory signaling that is widely known to be neurotoxic to brain tissue $[52,53]$. TGF $\beta$ has been shown to act on microglia in an autocrine manner and maintain microglial quiescence [54]. It has also been shown that microglia-derived TGF $\beta$ enhanced the invasiveness and tumorigenicity of the glioma cells and siRNA-mediated knockdown of TGF $\beta$ Receptor II in glioma cells disrupted this tumor promoting effect of TGF $\beta$ [30]. The present study shows increased levels of total and pSMAD2/3, which mediate TGF $\beta$ signaling pathway, in microglia after GCM treatment in vitro. While the roles of SMAD2/3 have been widely studied in microglia $[55,56]$, the role of SMAD4 in microglial activation, specifically in context of the TGF $\beta$ signaling has remained unclear. There is evidence showing that SMAD4 is upregulated in LPS-
A
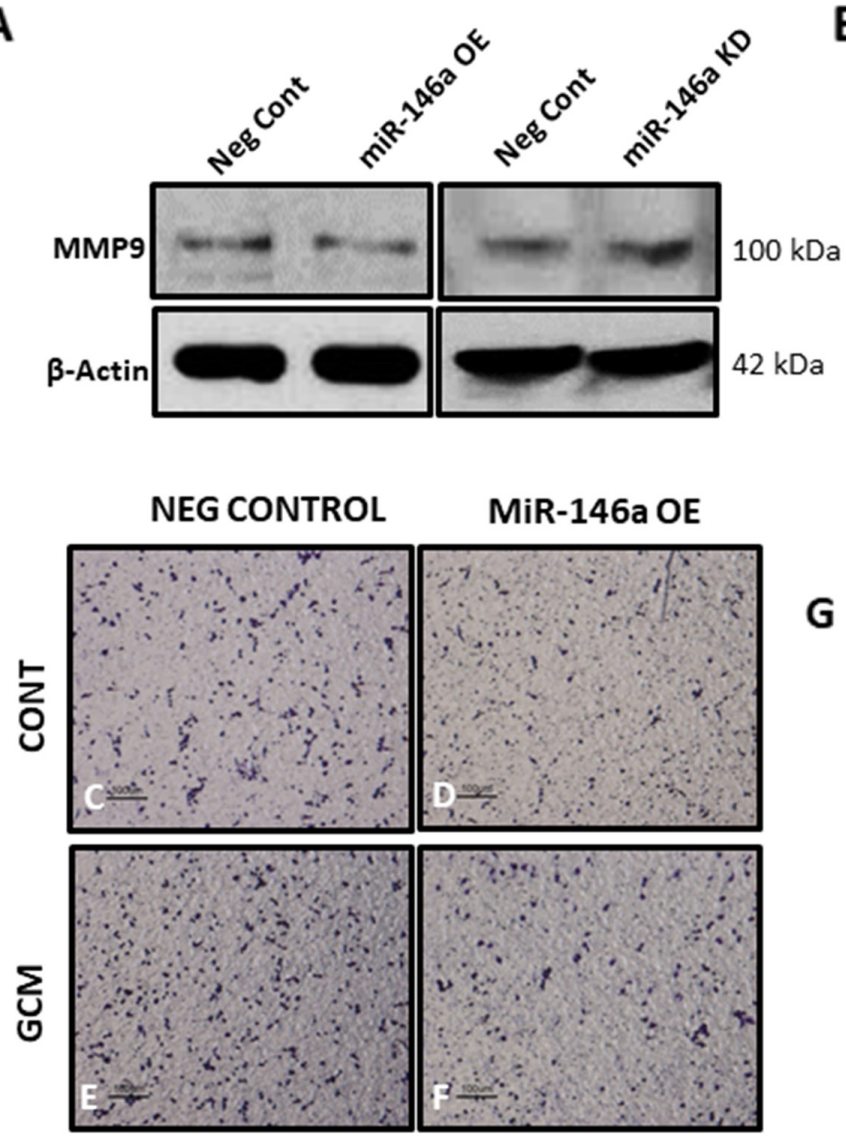

B

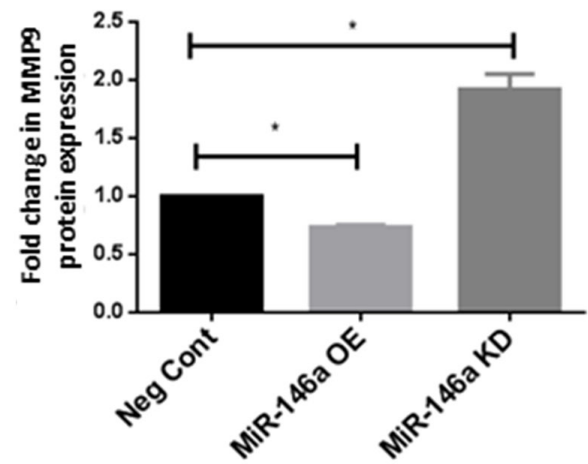

G

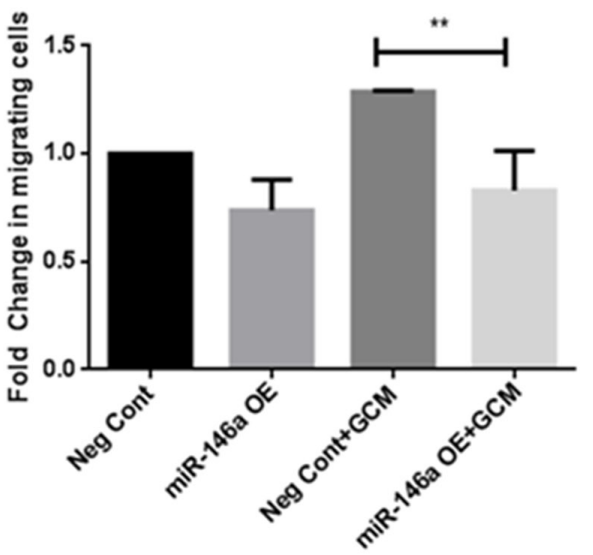

Figure 9: MiR-146a alters expression of tumor supportive gene MMP9 in glioma associated microglia and suppressed microglial migration towards GCM. Overexpression of miR-146a suppressed expression of MMP9 at the protein level and conversely, inhibition of miR-146a in microglia was found to increase levels of MMP9 as depicted by immunoblotting and densitometry analysis (A, B). Data represent mean $\pm \mathrm{SD},(\mathrm{n}=3)$, Students $t$-test, ${ }^{*} p<0.05$. Image panel shows a decrease in the number of migrated microglial cells (purple) after overexpression of miR-146a in response to GCM as compared to Neg Cont cells (C-F). Histogram depicts fold change in migrating cells (G). Data represent mean $\pm \mathrm{SD},(\mathrm{n}=3),{ }^{* *} p<0.01$. MiR-146a OE- MiR-146a overexpression; MiR-146a KD-MiR-146a knockdown. 
activated microglia and acts as a negative feedback inhibitor of $\mathrm{NF} \kappa \mathrm{B}$, a pro-inflammatory signaling response in the activated microglia [57]. In the present study, glioma-associated microglia expressed SMAD4 in human glioblastoma tumors in vivo and microglia exposed to GCM showed increased expression of SMAD4 in vitro. This was further supported by an analysis of the data in The Cancer Genome Atlas which revealed an upregulated SMAD4 level in glioblastoma tumors as compared to normal brain samples. Further, shRNA-mediated silencing of SMAD4 in microglia was associated with a decrease in the expression of MMP9, an extracellular matrix metalloproteinase and suppression of microglial migration. This has been evidenced in hepatocellular carcinoma wherein knockdown of SMAD4 reduced migratory capacity and colony formation ability of the cancer cells [26]. SMAD4 has also been shown to control endodermal cell migration during embryonic development through regulation of extracellular matrix modelling enzymes, MMP9 and MMP14 [58]. In addition, SMAD4 silencing in pancreatic tumor cells and keratinocytes has been shown to abolish TGF $\beta$ induced migration [59], therefore highlighting a vital role for SMAD4 in microglial migration.

Microglial cells are highly secretory in nature. In the present study, microglia-derived growth factors in the conditioned medium were found to promote glioma cell viability in vitro. This is an important finding as it may lead to a novel therapeutic strategy which may focus on suppressing microglia-mediated tumorigenesis. Moreover, this study demonstrates that glioma-associated microglia promote tumorigenesis through SMAD4 expression, since glioma cells treated with conditioned medium derived from shSMAD4 microglial cells showed decreased viability. This decreased viability of glioma cells is also possible via SMAD4-induced negative regulation of NF- $\kappa$ B pathway in microglia, since recent studies have shown that SMAD4 knockdown in microglia induced pro-inflammatory cytokine, IL-6 in an NF- $\mathrm{BB}$ dependent manner [57]. Overall, these results indicate that the possible interaction between SMAD4 and NF- $\kappa$ B in glioma-associated microglia may determine the tumor progression.

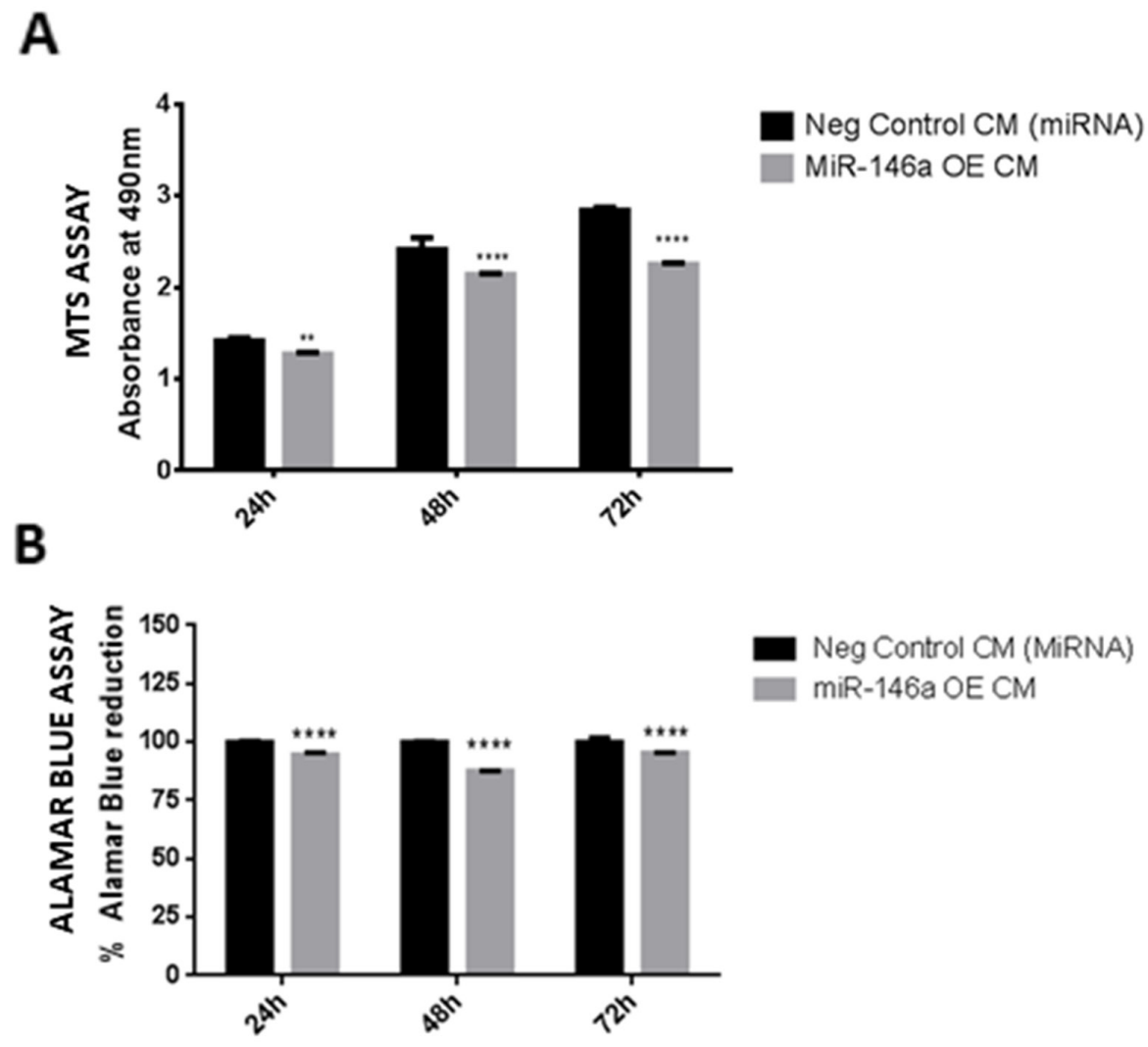

Figure 10: Effect of conditioned medium derived from miR-146a overexpression in microglia on viability of glioma cells. Histogram depicts MTS assay absorbance values 24, 48 and $72 \mathrm{~h}$ treatment of glioma cells with conditioned medium derived from miR-146a overexpression in microglia. A decrease in absorbance values at all time points indicates an inhibition of viability of glioma cells after treatment with medium from miR-146a overexpressed cells as compared to glioma cells treated with negative control (scrambled miRNA) transfected medium (A). Further, alamar blue assay results show a decrease in percentage of alamar blue reduction, indicating a suppression of glioma cell viability upon treatment with medium from miR-146a overexpressed microglia as compared to glioma cells treated with scrambled control transfected medium (B). Data represent Mean $\pm \mathrm{SD},(\mathrm{n}=4),{ }^{* *} p<0.01,{ }^{* * * *} p<0.0001$. 
The epigenetic regulation of SMAD4 was investigated, as these mechanisms provide an additional layer of post-transcriptional control. In this study, SMAD4 was found to be targeted by miR-146a in microglia. MiR146a, a miRNA enriched in immune cells, is known to be upregulated in activated microglia and macrophages in pathological conditions such as infection [41], ischemic stroke [60] and Alzheimer's disease [40, 61]. Several studies have shown that miR-146a modulates the innate immune response of activated microglial cells through regulation of the pro-inflammatory transcription factor, NFкB $[41,62]$. Recently, the miRNA-146b, which shows sequence similarity with miR-146a has been shown to inhibit glioma growth in vitro through modulation of its target EGFR [63]. Downregulation of miR-146a in gliomaassociated microglia as observed in the present study may favour tumorigenesis through increased expression of SMAD4 and its downstream genes which are involved in tumor progression. This also indicates that the gliomaassociated microglia do not exhibit activated microglial phenotype as observed in other neuropathologies such as Alzheimer's and stroke. Functional studies further confirmed that miR-146a is a negative regulator of tumorigenic gene expression in microglia via its target SMAD4, as its overexpression in microglia resulted in suppression of MMP9, which is a tumorigenic factor that promotes migration of microglia towards GCM and the glioma viability in vitro.

As the immune cell of the brain, microglia show complex phenotypes in the brain tumor and did not reject or phagocytose the tumor cells. Instead, they conglomerate within the tumor core and support the tumor progression. It is thus imperative to study microglial function in context of different molecular and genetic subtypes of glioblastoma. In this regard, this study shows robust expression of SMAD4 in glioblastoma tumors and in glioma-associated microglia. It has also been demonstrated that SMAD4 which was found to be post-transcriptionally regulated by miR-146a, regulates the migration of microglial cells in response to glioma conditioned medium. This study further established that miR-146a suppresses tumorigenic gene, MMP9 in gliomaassociated microglia and glioma cell viability through its target SMAD4 (Figure 11). Further in vivo studies are required to evaluate the therapeutic effect of miR-146a and SMAD4 on glioma growth and progression.

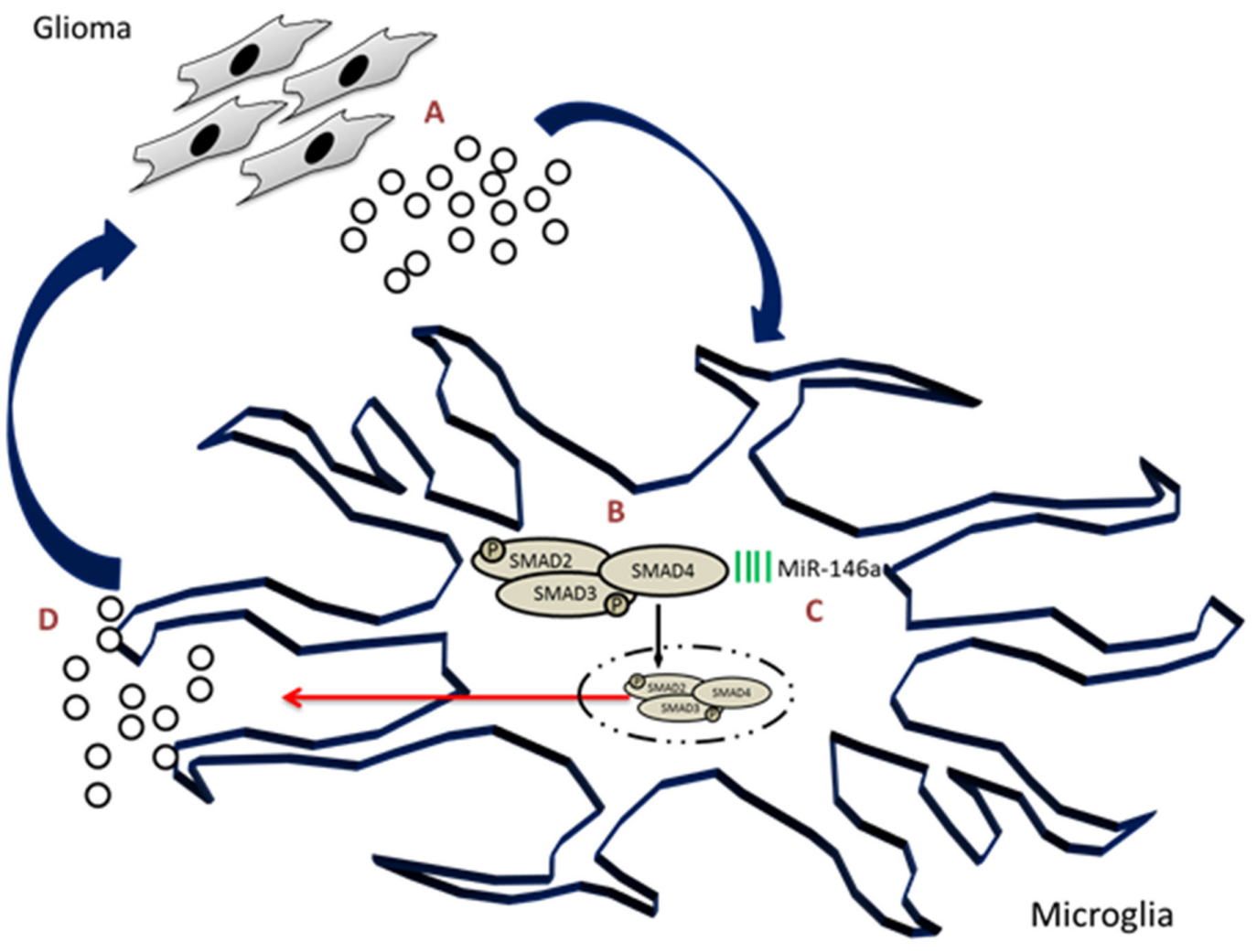

Figure 11: SMAD4, regulated by microRNA-146a, promotes microglial cell migration and tumor progression in glioma environment. Glioma cells secrete a number of factors including TGF $\beta$ (A) that activates the TGF $\beta$ pathway in microglia associated with glioma. Glioma conditioned medium was found to induce phosphorylation of SMAD2/3 complex and increase the level of SMAD4 (B) in microglia. Concurrently, miR-146a which was found to target SMAD4, was downregulated in glioma associated microglia (C). Downregulation of miR-146a in glioma-associated microglia increases the levels of tumor supportive factors (D), including SMAD4 and MMP9 which promote glioma progression and microglial migration. 
Table 1: Tumor sample grade and type

\begin{tabular}{lll}
\hline Sample Name & Tumor Type & Tumor Grade \\
\hline GB-21 & Glioblastoma & grade IV \\
GB-22 & Glioblastoma & grade IV \\
GBO-24 & Glioblastoma with oligodendroglial component & grade IV \\
GB-25 & Glioblastoma & grade IV \\
GBO-26 & Glioblastoma with oligodendroglioma & grade IV \\
GB-28 & Glioblastoma & grade IV \\
GB-34 & Glioblastoma & grade IV \\
\hline
\end{tabular}

Table 2: Primer sequences

\begin{tabular}{lll}
\hline Gene & Forward Primer & Reverse Primer \\
\hline SMAD4 & TCCAACACCCGCCAAGTAAT & GCTGGCTGAGCAGTAAATCC \\
MMP9 & GCGTGTCTGGAGATTCGACTT & TATCCACGCGAATGACGCT \\
$\beta$-Actin & GGATTCCATACCCAAGAAGGA & GGATTCCATACCCAAGAAGGA \\
\hline
\end{tabular}

\section{MATERIALS AND METHODS}

\section{Human tissue samples}

Graded brain tumor specimens were obtained with written informed consent, as part of a study protocol approved by the SingHealth Centralised Institutional Review Board A and the National Healthcare Group Domain-Specific Review Board A (Table 1). All protocols were approved by the Institutional Review Board, National University of Singapore. Use of glioblastoma human tissues was reviewed and approved by the National University of Singapore Institutional Review Board (NUSIRB Reference Code: B-16-049E).

\section{Immunofluorescence}

Human tumor sections were fixed, frozen, sectioned (7 $\mu \mathrm{m}$ thick) and mounted onto slides. Tissue sections were blocked in 3\% bovine serum albumin (BSA) solution in phosphate-buffered-saline (PBS) containing 0.3\% Triton-X (TX). Primary antibody against the full length human SMAD4 protein was a kind gift from Dr. Lu Lei from the Nanyang Technological University, Singapore. Sections were incubated with primary antibodies in $1 \%$ BSA overnight at $4^{\circ} \mathrm{C}$ at the following concentrations: SMAD4-1:300, Iba1-1:50 (Abcam, ab5076). Further, sections were stained with 4',6-diamidino-2-phenylindole (DAPI) (1:5000) and mounted with a fluorescent mounting medium. Fluorescence images were captured using a confocal microscope (Olympus, FV1000 Fluoview). Iba1 positive cell bodies showing a well-defined DAPI stained nuclei were manually counted across 4 fields of the tumor section and plotted as a percentage of total DAPI cell nuclei.

\section{Cell culture}

BV2 murine microglial cells and C6 rat astrocytoma cells obtained from American Tissue type Culture Collection (ATCC) were cultured in DMEM supplemented with $10 \%$ fetal bovine serum (FBS). Cells were maintained in a $5 \% \mathrm{CO}_{2}$ incubator at $37^{\circ} \mathrm{C}$ and regularly passaged with Trypsin-EDTA solution to allow healthy growth of cells.

\section{Preparation of glioma conditioned medium (GCM)}

To mimic a glioma microenvironment in vitro, microglial BV2 cells were treated with conditioned medium from the C6 cell line [64, 65]. Briefly, C6 cells were seeded in $10 \mathrm{~cm}$ culture dishes at a density of $2 \times 10^{6}$ cells. Cells were allowed to settle overnight and DMEM supplemented with $10 \%$ FBS was added to the culture the next day. Culture supernatant was collected after $48 \mathrm{~h}$ and filtered through a $0.22 \mu \mathrm{m}$ filter to remove cellular debris. GCM was stored at $-80^{\circ} \mathrm{C}$ and freeze-thaw cycles were minimized.

\section{Generation of SMAD4 knockdown stable cells in microglia}

Stable knockdown of SMAD4 was performed by lentiviral mediated transduction of SMAD4 specific shRNA in BV2 microglial cells. Microglial cells were transduced with 4 shRNA individual clones 
(Dharmacon, GE Healthcare) against the SMAD4 gene (Accession Number: NM_008540). Selection pressure was applied $48 \mathrm{~h}$ after transduction using puromycin at the concentration of $2 \mu \mathrm{g} / \mathrm{ml}$. Cells were maintained in puromycin containing medium for 6-10 days and expanded [66]. Efficiency of knockdown in microglia was confirmed using western blotting analysis and the shSMAD4 clone that induced maximal knockdown, shSMAD4_2, was selected for further analysis (Supplementary Figure 1).

\section{RNA extraction, cDNA conversion and quantitative real-time PCR (miRNA)}

RNA was isolated from the BV2 cells after transfection or treatment, using miRNeasy Mini Kit (Qiagen, Cat No: 217004) as per the manufacturer's instructions. RNA isolate (10ng) was used for conversion of miRNA to cDNA using Universal cDNA Synthesis Kit II (Exiqon, Cat No: 203301). Quantification of miRNA expression in control and GCM treated groups was carried out using ExiLENT SYBR ${ }^{\circledR}$ Green master mix (Exiqon, Cat No: 203421). LNA-modified miR-146a-5p primers (Exiqon, Cat No: 204688) and small nuclear U6 RNA primers (Exiqon, Cat No: 203907) were used for miRNA real time PCR.

\section{cDNA conversion and quantitative Real-time PCR (mRNA)}

The total RNA (2000ng) was converted to cDNA for gene expression analysis using a master mix consisting of M-MLV Reverse transcriptase enzyme (Promega, Cat No: M170A), M-MLV Reverse Transcriptase 5X Reaction Buffer (Promega, Cat No: M531A), dNTP (Promega, Cat No: U1511) and RNasin ${ }^{\circledR}$ Ribonuclease inhibitor (Promega, Cat No: N2111) in a $25 \mu \mathrm{l}$ reaction volume. The qRT-PCR for gene expression was performed using Fast SYBR Green Master Mix (ThermoFisher Scientific, Cat No: 4385614) with 1:10 ratio dilution of cDNA in nuclease-free water. Primer sequences for PCR reactions are given in Table 2. Fold change between control and experimental groups was calculated as per $2^{-\Delta \Delta \mathrm{Ct}}$ method [67]. All PCR reactions were carried out in a real time Applied Biosystems PCR system (Life Technologies, Model No: 7900HT).

\section{Migration assay}

The Transwell migration assay was carried out to assess the migratory potential of microglia towards GCM, TGF $\beta$ and EGF. 40,000 microglial cells were seeded in the upper chamber of the Transwell migration insert (Corning, Cat No:3422) and was placed in the lower chamber containing glioma conditioned medium and medium containing TGF $\beta$ (PeproTech, Cat No 100-21C) and human recombinant EGF (Life Technologies, PHG0311).
The cells were allowed to migrate for $15 \mathrm{~h}$. Inserts were fixed in $100 \%$ methanol for $10 \mathrm{~min}$ and stained for visualization using $0.5 \%$ cresyl violet solution. Cells on the upper membrane of the insert were removed using a cotton swab. 5 random fields from 3 biological replicates were quantified and the results are plotted as fold change between treatment and control groups.

\section{Transfection of miRNA mimics and inhibitors}

BV2 cells were plated at a density of $2 \times 10^{5}$ in 6-well plates and gain-of and loss-of-function studies of miR-146a-5p was carried out using miRNA mimics (Ambion, Cat No: 4464066) and miRNA inhibitors (Exiqon, Cat No: 4100679-001). BV2 cells were also transfected with scrambled mimics (Ambion, Cat No: 4464058) or inhibitors (Exiqon, Cat No: 199006-001) as negative controls. The mimic and inhibitors complexes for transfection were prepared using X-tremeGENE siRNA Transfection Reagent (Roche, Cat No: 04476093001) in Opti-MEM medium at concentrations of 20 and 40nM, respectively. RNA and protein analyses were performed at $48 \mathrm{~h}$ and $72 \mathrm{~h}$ post transfection, respectively.

\section{Western blotting}

Protein extracts from BV2 microglial cells were obtained using a cocktail of M-PER ${ }^{\mathrm{TM}}$ Mammalian Protein Extraction Reagent (ThermoFisher Scientific, Cat No: 78501), Halt ${ }^{\mathrm{TM}}$ Protease Inhibitor (ThermoFisher Scientific, Cat No: 78430) and phosphatase inhibitor (ThermoFisher Scientific, Cat No: 78427). Protein quantification was performed by Bradford assay using the Bio-Rad protein Assay Kit (Bio-Rad, Cat No: 5000001). Total protein lysate $(30 \mu \mathrm{g})$ was denatured at $95^{\circ} \mathrm{C}$ for $10 \mathrm{~min}$. Proteins were loaded onto a $10 \%$ SDS-polyacrylamide gel (PAGE) electrophoresis setup and transferred to membranes (BioRad, Cat No: 162-0177). Blocking of non-specific sites on the membrane was done using $5 \%$ milk or bovine serum albumin (BSA). Membranes were incubated overnight at $4^{\circ} \mathrm{C}$ with primary antibodies as follows: SMAD4-1:1000 (Cell Signaling Technology, Cat No: 9515), VEGFa-1:500 (SantaCruz, Cat No: sc-152) and MMP9-1:2000 (EMD Millipore, Cat No: AB19016) and subsequently incubated with horseradish peroxidase conjugated secondary antibodies (ThermoFisher Scientific, Cat No: 31430, Cat No: 31460) 1h. Pico Chemiluminescent substrate (ThermoFisher Scientific, Cat No: 37070) was used to develop the blots and the protein expression level was quantified densitometrically (Bio-Rad Quantity One ${ }^{\circledR}$ 1-D Analysis Software, Cat No: 1709600).

\section{Luciferase assay}

A luciferase assay was performed to verify if miR-146a targets SMAD4 mRNA. BV2 microglial cells were plated at a density of 20,000 cells in 24 well plates. The luciferase 
vector containing the 3 'UTR of SMAD4 was commercially purchased from GeneCopoeia (Cat No: MmiT027594). Cells were co-transfected with mimics and scrambled probes $(30 \mathrm{~nm})$ and luciferase vector (1000ng) and the medium containing secreted luciferase was collected at $24 \mathrm{~h}$. The Secrete-Pair Dual Luminescence Assay Kit (GeneCopoeia Cat No: SPDA-D010) was used to determine luminescence of secreted Gaussia luciferase (GLuc). A secondary reporter, secreted alkaline phosphatase (SEAP), served as an internal control. GLuc/SEAP ratio was determined to measure the luminescence output of the transfected sample.

\section{Immunocytochemistry}

BV2 microglial cells were grown on poly-L-lysine coated coverslips. Following transfection and/or treatment, cells were fixed with $4 \%$ paraformaldehyde for $15 \mathrm{~min}$ at room temperature. Permeabilization of cell membranes was achieved using $0.1 \%$ Triton-X containing PBS. Following this, the slides were blocked using 5\% normal goat serum and incubated overnight at $4^{\circ} \mathrm{C}$ with the following antibodies- SMAD4-1:100 (Santa Cruz, sc-7966), pSMAD2/3-1:200 (Cell signaling technology, Cat No: 8828) and SMAD2/3-1:200 (Cell Signaling Technology, Cat No: 8685). Following this, cells were incubated with fluorophore tagged secondary antibodies: anti-rabbit $\mathrm{Cy} 3$ (Sigma, Cat No: c2306), anti-mouse Cy3 (Sigma, Cat No: C2181) and FITC conjugated lectin (Sigma, Cat No: L0401) was used as a marker for microglial cells. Cell nuclei were counterstained with DAPI for visualization. Fluorescence images were captured using a confocal microscope (Olympus, FV1000 Fluoview).

\section{ELISA based quantification of TGF $\beta$ in GCM}

TGF $\beta$ in the C6 glioma conditioned medium (GCM) was quantified using the Quantikine ELISA Kit (RND Systems, MB100B) as per the manufacturer's instructions. Briefly, latent TGF $\beta 1$ was activated to its immunoreactive form by addition of $20 \mu \mathrm{l}$ of $1 \mathrm{M} \mathrm{HCl}$ to $100 \mu \mathrm{l}$ of the GCM, and subsequently neutralized by adding $20 \mu \mathrm{l}$ of $1.2 \mathrm{~N}$ $\mathrm{NaOH}$. The TGF $\beta 1$ standard was reconstituted and serially diluted using the diluent solution provided in the kit. $50 \mu \mathrm{l}$ of GCM and the TGF $\beta 1$ standard samples were added to the TGF- $\beta 1$ antibody pre-coated ELISA plate and incubated for $2 \mathrm{~h}$. Subsequently, the samples were discarded, and the wells were thoroughly washed using wash buffer. Next, $100 \mu \mathrm{l}$ of the TGF $\beta 1$ conjugate was added to each well and incubated for $2 \mathrm{~h}$. Following washing, the plate was incubated with substrate solution, and reaction was stopped using the stop solution provided in the kit. The optical density was measured at $450 \mathrm{~nm}$ using a plate reader.

\section{MTS and alamar blue cell viability assay}

In order to evaluate the effect of SMAD4 knockdown in microglia on glioma cell viability, an MTS and alamar blue assay was performed. Conditioned medium was collected from control microglia (microglial CM) and from microglia after knockdown of SMAD4 (shSMAD4-CM) or miR-146a overexpression (MiR-146a OE-CM). Conditioned medium from microglia transduced with the empty vector (Neg Control CM (stables)) and the scrambled probes (Neg Control CM (miRNA)) served as controls. About 10,000 of C6 glioma cells were seeded in 96-well plates and treated with the conditioned medium from different groups. Post 24, 48 and $72 \mathrm{~h}$ of treatment, $20 \mu \mathrm{l}$ of MTS reagent (Promega, Cat No. G358C) was added to the cells and incubated at $37^{\circ} \mathrm{C}$ for $2 \mathrm{~h}$. Following this, absorbance was read at 490 nm in a 96-well plate reader. The alamar blue assay was performed by adding $10 \mu \mathrm{l}$ of the alamar blue reagent (ThermoFisher Scientific, Cat No. DAL1100) to the cells after treatment with conditioned medium. Absorbance was read at $570 \mathrm{~nm}$ and normalized against absorbance at $600 \mathrm{~nm}$. The results are plotted as a percentage of alamar blue reduction.

\section{Statistical analysis}

Data from at least three biological replicates were analyzed using GraphPad Prism and Microsoft Excel software and represented as mean \pm S.D. In comparing 2 experimental groups, the Student's $t$-test was used. Multiple groups were analyzed using one-way or two-way ANOVA tests, followed by post-hoc Tukey's and Sidak's test. Data sets were considered significant at $p<0.05$.

\section{ACKNOWLEDGMENTS}

The authors would like to acknowledge Ms. Ashwini Karanth for some technical assistance in the project.

\section{CONFLICTS OF INTEREST}

The authors declare no conflicts of interest.

\section{FUNDING}

Authors would like to acknowledge the funding provided by NUS Medicine strategic grant (Memory Network Program WBS: R-185-000-271-646) and Academic Research Fund (AcRF) Tier-1 Grant (WBS No: R-181-000-153-112). Ms. Aparna Karthikeyan is supported by the NUS Research scholarship. C Tang and BT Ang are supported by the Singapore Ministry of Health's National Medical Research Council under its Translational and Clinical Research Flagship Programme- Tier 1 (Project No: NMRC/TCR/016-NNI/2016).

\section{REFERENCES}

1. Shi Y, Ping YF, Zhang X, Bian XW. Hostile takeover: glioma stem cells recruit TAMs to support tumor progression. Cell Stem Cell. 2015; 16:219-20. 
2. Erreni M, Solinas G, Brescia P, Osti D, Zunino F, Colombo P, Destro A, Roncalli M, Mantovani A, Draghi R, Levi D, Rodriguez Y Baena R, Gaetani P, et al. Human glioblastoma tumours and neural cancer stem cells express the chemokine CX3CL1 and its receptor CX3CR1. Eur J Cancer. 2010; 46:3383-92.

3. Svensson A, Özen I, Genové G, Paul G, Bengzon J. Endogenous brain pericytes are widely activated and contribute to mouse glioma microvasculature. PLoS One. 2015; 10:e123553.

4. Graeber MB, Scheithauer BW, Kreutzberg GW. Microglia in brain tumors. Glia. 2002; 40:252-59.

5. Roggendorf W, Strupp S, Paulus W. Distribution and characterization of microglia/macrophages in human brain tumors. Acta Neuropathol. 1996; 92:288-93.

6. Dheen ST, Kaur C, Ling EA. Microglial activation and its implications in the brain diseases. Curr Med Chem. 2007; 14:1189-97.

7. Francos-Quijorna I, Amo-Aparicio J, Martinez-Muriana A, López-Vales R. IL-4 drives microglia and macrophages toward a phenotype conducive for tissue repair and functional recovery after spinal cord injury. Glia. 2016; 64:2079-92.

8. Miron VE, Boyd A, Zhao JW, Yuen TJ, Ruckh JM, Shadrach JL, van Wijngaarden P, Wagers AJ, Williams A, Franklin RJ, Ffrench-Constant C. M2 microglia and macrophages drive oligodendrocyte differentiation during CNS remyelination. Nat Neurosci. 2013; 16:1211-18.

9. Kumar A, Alvarez-Croda DM, Stoica BA, Faden AI, Loane DJ. Microglial/macrophage polarization dynamics following traumatic brain injury. J Neurotrauma. 2016; 33:1732-50.

10. Tang Y, Le W. Differential roles of M1 and M2 microglia in neurodegenerative diseases. Mol Neurobiol. 2016; 53:1181-94.

11. Grimaldi A, D’Alessandro G, Golia MT, Grössinger EM, Di Angelantonio S, Ragozzino D, Santoro A, Esposito V, Wulff $\mathrm{H}$, Catalano M, Limatola C. KCa3.1 inhibition switches the phenotype of glioma-infiltrating microglia/macrophages. Cell Death Dis. 2016; 7:e2174.

12. Prosniak M, Harshyne LA, Andrews DW, Kenyon LC, Bedelbaeva K, Apanasovich TV, Heber-Katz E, Curtis MT, Cotzia P, Hooper DC. Glioma grade is associated with the accumulation and activity of cells bearing M2 monocyte markers. Clin Cancer Res. 2013; 19:3776-86.

13. Szulzewsky F, Pelz A, Feng X, Synowitz M, Markovic D, Langmann T, Holtman IR, Wang X, Eggen BJ, Boddeke HW, Hambardzumyan D, Wolf SA, Kettenmann H. Gliomaassociated microglia/macrophages display an expression profile different from M1 and M2 polarization and highly express Gpnmb and Spp1. PLoS One. 2015; 10:e0116644.

14. Gabrusiewicz K, Rodriguez B, Wei J, Hashimoto Y, Healy LM, Maiti SN, Thomas G, Zhou S, Wang Q, Elakkad A, Liebelt BD, Yaghi NK, Ezhilarasan R, et al.
Glioblastoma-infiltrated innate immune cells resemble M0 macrophage phenotype. JCI Insight. 2016; 1:1.

15. Ellert-Miklaszewska A, Dabrowski M, Lipko M, Sliwa M, Maleszewska M, Kaminska B. Molecular definition of the pro-tumorigenic phenotype of glioma-activated microglia. Glia. 2013; 61:1178-90.

16. Hambardzumyan D, Gutmann DH, Kettenmann H. The role of microglia and macrophages in glioma maintenance and progression. Nat Neurosci. 2016; 19:20-27.

17. Attisano L, Wrana JL. Signal transduction by the TGF- $\beta$ superfamily. Science. 2002; 296:1646-47.

18. Chung KS, Cho SH, Shin JS, Kim DH, Choi JH, Choi SY, Rhee YK, Hong HD, Lee KT. Ginsenoside Rh2 induces cell cycle arrest and differentiation in human leukemia cells by upregulating TGF- $\beta$ expression. Carcinogenesis. 2013; 34:331-40.

19. Craven KE, Gore J, Wilson JL, Korc M. Abstract 3400 : an angiogenesis gene signature points to active TGF-beta/ JAK signaling pathways in a subset of human pancreatic ductal adenocarcinoma cancer patients that are distinct from pathways in pancreatic neuroendocrine tumors. Cancer Res. 2016; 76:3400.

20. Yuan JH, Yang F, Wang F, Ma JZ, Guo YJ, Tao QF, Liu F, Pan W, Wang TT, Zhou CC, Wang SB, Wang YZ, Yang Y, et al. A long noncoding RNA activated by TGF- $\beta$ promotes the invasion-metastasis cascade in hepatocellular carcinoma. Cancer Cell. 2014; 25:666-81.

21. Juang YL, Jeng YM, Chen CL, Lien HC. PRRX2 as a novel TGF- $\beta$-induced factor enhances invasion and migration in mammary epithelial cell and correlates with poor prognosis in breast cancer. Mol Carcinog. 2016; 55:2247-59.

22. Tarhoni I, Lobato GC, Fhied C, Borgia J, Pergande M, Chai YW. Abstract 1690: IGF-1 and TGF- $\beta$ promote EMT and angiogenesis in $3 \mathrm{D}$ cultures of lung adenocarcinoma cells: a pilot study. Cancer Res. 2016; 76:1690.

23. Bruna A, Darken RS, Rojo F, Ocaña A, Peñuelas S, Arias A, Paris R, Tortosa A, Mora J, Baselga J, Seoane J. High TGFbeta-Smad activity confers poor prognosis in glioma patients and promotes cell proliferation depending on the methylation of the PDGF-B gene. Cancer Cell. 2007; 11:147-60.

24. Eichhorn PJ, Rodón L, Gonzàlez-Juncà A, Dirac A, Gili M, Martínez-Sáez E, Aura C, Barba I, Peg V, Prat A, Cuartas I, Jimenez J, García-Dorado D, et al. USP15 stabilizes TGF- $\beta$ receptor I and promotes oncogenesis through the activation of TGF- $\beta$ signaling in glioblastoma. Nat Med. 2012; 18:429-35.

25. Verhaak RG, Hoadley KA, Purdom E, Wang V, Qi Y, Wilkerson MD, Miller CR, Ding L, Golub T, Mesirov JP, Alexe G, Lawrence M, O'Kelly M, et al, and Cancer Genome Atlas Research Network. Integrated genomic analysis identifies clinically relevant subtypes of glioblastoma characterized by abnormalities in PDGFRA, IDH1, EGFR, and NF1. Cancer Cell. 2010; 17:98-110. 
26. Hernanda PY, Chen K, Das AM, Sideras K, Wang W, Li J, Cao W, Bots SJ, Kodach LL, de Man RA, Ijzermans JN, Janssen HL, Stubbs AP, et al. SMAD4 exerts a tumorpromoting role in hepatocellular carcinoma. Oncogene. 2015; 34:5055-68.

27. Fullerton PT Jr, Creighton CJ, Matzuk MM. Insights into SMAD4 loss in pancreatic cancer from inducible restoration of TGF- $\beta$ signaling. Mol Endocrinol. 2015; 29:1440-53.

28. Bardeesy N, Cheng KH, Berger JH, Chu GC, Pahler J, Olson P, Hezel AF, Horner J, Lauwers GY, Hanahan D, DePinho RA. Smad4 is dispensable for normal pancreas development yet critical in progression and tumor biology of pancreas cancer. Genes Dev. 2006; 20:3130-46.

29. Joseph JV, Balasubramaniyan V, Walenkamp A, Kruyt FA. TGF- $\beta$ as a therapeutic target in high grade gliomas - promises and challenges. Biochem Pharmacol. 2013; 85:478-85.

30. Wesolowska A, Kwiatkowska A, Slomnicki L, Dembinski M, Master A, Sliwa M, Franciszkiewicz K, Chouaib S, Kaminska B. Microglia-derived TGF-beta as an important regulator of glioblastoma invasion - an inhibition of TGFbeta-dependent effects by shrna against human TGF-beta type II receptor. Oncogene. 2008; 27:918-30.

31. Jadhav SP, Kamath SP, Choolani M, Lu J, Dheen ST. microRNA-200b modulates microglia-mediated neuroinflammation via the cJun/MAPK pathway. J Neurochem. 2014; 130:388-401.

32. Patnala R, Arumugam TV, Gupta N, Dheen ST. HDAC inhibitor sodium butyrate-mediated epigenetic regulation enhances neuroprotective function of microglia during ischemic stroke. Mol Neurobiol. 2017; 54:6391-6411.

33. Karthikeyan A, Patnala R, Jadhav SP, Eng-Ang L, Dheen ST. Micrornas: key players in microglia and astrocyte mediated inflammation in cns pathologies. Curr Med Chem. 2016; 23:3528-46.

34. Taganov KD, Boldin MP, Chang KJ, Baltimore D. NF-kappaB-dependent induction of microRNA miR-146, an inhibitor targeted to signaling proteins of innate immune responses. Proc Natl Acad Sci USA. 2006; 103:12481-86.

35. Iyer A, Zurolo E, Prabowo A, Fluiter K, Spliet WG, van Rijen PC, Gorter JA, Aronica E. MicroRNA-146a: a key regulator of astrocyte-mediated inflammatory response. PLoS One. 2012; 7: e44789.

36. Saba R, Sorensen DL, Booth SA. MicroRNA-146a: a dominant, negative regulator of the innate immune response. Front Immunol. 2014; 5:578.

37. Mei J, Bachoo R, Zhang CL. MicroRNA-146a inhibits glioma development by targeting Notch1. Mol Cell Biol. 2011; 31:3584-92.

38. Massagué J, Seoane J, Wotton D. Smad transcription factors. Genes Dev. 2005; 19:2783-810.

39. Rhodes DR, Yu J, Shanker K, Deshpande N, Varambally R, Ghosh D, Barrette T, Pandey A, Chinnaiyan AM. ONCOMINE: a cancer microarray database and integrated data-mining platform. Neoplasia. 2004; 6:1-6.
40. Lukiw WJ, Zhao Y, Cui JG. An NF-kappaB-sensitive micro RNA-146a-mediated inflammatory circuit in Alzheimer disease and in stressed human brain cells. J Biol Chem. 2008; 283:31315-22.

41. Saba R, Gushue S, Huzarewich RL, Manguiat K, Medina S, Robertson C, Booth SA. MicroRNA 146a (miR-146a) is over-expressed during prion disease and modulates the innate immune response and the microglial activation state. PLoS One. 2012; 7:e30832.

42. Parkhurst CN, Yang G, Ninan I, Savas JN, Yates JR 3rd, Lafaille JJ, Hempstead BL, Littman DR, Gan WB. Microglia promote learning-dependent synapse formation through brain-derived neurotrophic factor. Cell. 2013; 155:1596-609.

43. Schafer DP, Lehrman EK, Kautzman AG, Koyama R, Mardinly AR, Yamasaki R, Ransohoff RM, Greenberg ME, Barres BA, Stevens B. Microglia sculpt postnatal neural circuits in an activity and complement-dependent manner. Neuron. 2012; 74:691-705.

44. Paolicelli RC, Bolasco G, Pagani F, Maggi L, Scianni M, Panzanelli P, Giustetto M, Ferreira TA, Guiducci E, Dumas L, Ragozzino D, Gross CT. Synaptic pruning by microglia is necessary for normal brain development. Science. 2011; 333:1456-58.

45. Kaur C, Rathnasamy G, Ling EA. Biology of microglia in the developing brain. J Neuropathol Exp Neurol. 2017; 76:736-53.

46. Zhai H, Heppner FL, Tsirka SE. Microglia/macrophages promote glioma progression. Glia. 2011; 59:472-85.

47. Resende FF, Bai X, Del Bel EA, Kirchhoff F, Scheller A, Titze-de-Almeida R. Evaluation of TgH(CX3CR1-EGFP) mice implanted with mCherry-GL261 cells as an in vivo model for morphometrical analysis of glioma-microglia interaction. BMC Cancer. 2016; 16:72.

48. Richter N, Wendt S, Georgieva PB, Hambardzumyan D, Nolte C, Kettenmann H. Glioma-associated microglia and macrophages/monocytes display distinct electrophysiological properties and do not communicate via gap junctions. Neurosci Lett. 2014; 583:130-35.

49. Zheng Y, Yang W, Aldape K, He J, Lu Z. Epidermal growth factor (EGF)-enhanced vascular cell adhesion molecule-1 (VCAM-1) expression promotes macrophage and glioblastoma cell interaction and tumor cell invasion. J Biol Chem. 2013; 288:31488-95.

50. Nolte C, Kirchhoff F, Kettenmann H. Epidermal growth factor is a motility factor for microglial cells in vitro: evidence for EGF receptor expression. Eur J Neurosci. 1997; 9:1690-98.

51. De Simone R, Ambrosini E, Carnevale D, Ajmone-Cat MA, Minghetti L. NGF promotes microglial migration through the activation of its high affinity receptor: modulation by TGF- $\beta$. J Neuroimmunol. 2007; 190:53-60.

52. Suzumura A, Sawada M, Yamamoto H, Marunouchi T. Transforming growth factor-beta suppresses activation 
and proliferation of microglia in vitro. J Immunol. 1993; 151:2150-58.

53. 53. Norden DM, Fenn AM, Dugan A, Godbout JP. TGF $\beta$ produced by IL-10 redirected astrocytes attenuates microglial activation. Glia. 2014; 62:881-95.

54. Spittau B, Wullkopf L, Zhou X, Rilka J, Pfeifer D, Krieglstein K. Endogenous transforming growth factor-beta promotes quiescence of primary microglia in vitro. Glia. 2013; 61:287-300.

55. Le Y, Iribarren P, Gong W, Cui Y, Zhang X, Wang JM. TGF- $\beta 1$ disrupts endotoxin signaling in microglial cells through Smad3 and MAPK pathways. J Immunol. 2004; 173:962-68.

56. Tichauer JE, von Bernhardi R. Transforming growth factor- $\beta$ stimulates $\beta$ amyloid uptake by microglia through Smad3-dependent mechanisms. J Neurosci Res. 2012; 90:1970-80.

57. Liu X, Qin Y, Dai A, Zhang Y, Xue H, Ni H, Han L, Zhu L, Yuan D, Tao T, Cao M. SMAD4 is involved in the development of endotoxin tolerance in microglia. Cell Mol Neurobiol. 2016; 36:777-88.

58. Costello I, Biondi CA, Taylor JM, Bikoff EK, Robertson EJ. Smad4-dependent pathways control basement membrane deposition and endodermal cell migration at early stages of mouse development. BMC Dev Biol. 2009; 9:54.

59. Levy L, Hill CS. Smad4 dependency defines two classes of transforming growth factor $\{\beta\}$ (TGF- $\{\beta\}$ ) target genes and distinguishes TGF- $\{\beta\}$-induced epithelial-mesenchymal transition from its antiproliferative and migratory responses. Mol Cell Biol. 2005; 25:8108-25.

60. Kong H, Omran A, Ashhab MU, Gan N, Peng J, He F, Wu L, Deng X, Yin F. Changes in microglial inflammationrelated and brain-enriched MicroRNAs expressions in response to in vitro oxygen-glucose deprivation. Neurochem Res. 2014; 39:233-43.
61. Alexandrov PN, Dua P, Lukiw WJ. Up-regulation of miRNA-146a in progressive, age-related inflammatory neurodegenerative disorders of the human CNS. Front Neurol. 2014; 5:181.

62. Deng M, Du G, Zhao J, Du X. miR-146a negatively regulates the induction of proinflammatory cytokines in response to Japanese encephalitis virus infection in microglial cells. Arch Virol. 2017; 162:1495-505.

63. Katakowski M, Buller B, Zheng X, Lu Y, Rogers T, Osobamiro O, Shu W, Jiang F, Chopp M. Exosomes from marrow stromal cells expressing miR-146b inhibit glioma growth. Cancer Lett. 2013; 335:201-04.

64. Kim YJ, Hwang SY, Hwang JS, Lee JW, Oh ES, Han IO. C6 glioma cell insoluble matrix components enhance interferon- $\gamma$-stimulated inducible nitric-oxide synthase/ nitric oxide production in BV2 microglial cells. J Biol Chem. 2008; 283:2526-33.

65. Shen X, Burguillos MA, Osman AM, Frijhoff J, CarrilloJiménez A, Kanatani S, Augsten M, Saidi D, Rodhe J, Kavanagh E, Rongvaux A, Rraklli V, Nyman U, et al. Glioma-induced inhibition of caspase-3 in microglia promotes a tumor-supportive phenotype. Nat Immunol. 2016; 17:1282-90.

66. Mallilankaraman $\mathrm{K}$, Cárdenas $\mathrm{C}$, Doonan $\mathrm{PJ}$, Chandramoorthy HC, Irrinki KM, Golenár T, Csordás G, Madireddi P, Yang J, Müller M, Miller R, Kolesar JE, Molgó $\mathrm{J}$, et al. MCUR1 is an essential component of mitochondrial $\mathrm{Ca} 2+$ uptake that regulates cellular metabolism. Nat Cell Biol. 2012; 14:1336-43.

67. Livak KJ, Schmittgen TD. Analysis of relative gene expression data using real-time quantitative PCR and the $2^{(-\Delta \Delta \mathrm{C}(\mathrm{T}))}$ Method. Methods. 2001; 25:402-08. 